\title{
Neodjudezmo en la lírica latinoamericana disidente: la construcción de registros intersticiales entre la autotraducción y el glosario'
}

\author{
Cynthia Gabbay \\ cynthia.gabbay@cmb.hu-berlin.de \\ https://orcid.org/0000-0002-6779-1375 \\ Instituto de Estudios Avanzados Le Studium Laboratorio Rémélice, \\ Universidad de Orléans, Orléans, Francia \\ Centre Marc Bloch, Universidad Humboldt de Berlín, Alemania
}

\begin{abstract}
Resumen
En el marco del exterminio de especies y culturas característico del Antropoceno-Capitaloceno y, entre ellos el de la cultura sefardí durante la Shoá, el artículo se pregunta acerca de la anunciada agonía de la lengua judeoespañola y el final de una era de lenguas menores nativas. Aborda el campo de la nueva poesía djudezma en América latina, así como el rol que juegan los artilugios metalingüísticos de la autotraducción y el glosario en los procesos de su producción. El artículo toma los casos de estudio Poemas de Estambul (2008) y El saco de Douglas (2011) de Denise León (Argentina), y Ansina (2015) de Myriam Moscona (México). El poemario Dibaxu (1994) de Juan Gelman es identificado no sólo como hipotexto principal de estas obras sino también como evento epistémico -productor intertextual de un nuevo saber-, de la literatura iberoamericana que juega el rol de artefacto decolonial porque aboga por desandar a través de la elección de una lengua otra, el ethos colonialista/cristianizador y expulsionista hispánico. Con relación a los mecanismos metalingüísticos identificados a la hora de publicar poesía en neodjudezmo y en comparación con la propuesta de lectura intersticial de Gelman, el artículo evalúa el concepto de "textos duplicados" sugerido por J. Walsh Hokenson y M. Munson al pensar las literaturas bilingües y examina las manifestaciones translingüísticas de los textos, verificando sus efectos sobre la divergencia de género que plantea. Por último, postula que, al resistirse a la modernidad, en su disidencia, la poesía en neodjudezmo produce una vanguardia poética.
\end{abstract}

Palabras clave: judeoespañol; autotraducción; Denise León; Juan Gelman; Myriam Moscona; neodjudezmo; poesía latinoamericana.

1 Este trabajo se realiza en el marco del proyecto "Exponential Minor Literature: Neo-Djudezmo towards an Epistemic Recovery of the Jewish Poetic Archive", llevado a cabo en el Centro Marc Bloch de Berlín (Universidad Humboldt de Berlín). En él trabajo diversos textos literarios en judeoespañol contemporáneo en su relación con las lenguas o contextos culturales románicos.. 
Neo-djudezme dans la lyrique latino-américaine dissidente : la construction de registres interstitiels entre l'autotraduction et le glossaire

\title{
Résumé
}

Dans le contexte de l'extermination des espèces et des cultures, caractéristique de l'Anthropocène-Capitalocène et, parmi elles, celle de la culture sépharade pendant la Shoah, l'article s'interroge sur l'agonie annoncée de la langue judéo-espagnole et la fin d'une ère de langues naturelles mineures. Il aborde le domaine de la nouvelle poésie djudezme en Amérique latine, ainsi que le rôle joué par les engins métalinguistiques de l'autotraduction et le glossaire dans les processus de sa production. L'article pose ses inquisitions autour des études de cas Poemas de Estambul (2008) et El saco de Douglas (2011) de Denise León (Argentine), ainsi que Ansina (2015) de Myriam Moscona (Mexique). Le recueil de poésie Dibaxu (1994) de Juan Gelman est identifié non seulement comme le principal hypotexte de ces œuvres mais aussi comme un événement épistémique - producteur intertextuel d'un nouveau savoir - de la littérature ibéro-américaine qui joue le rôle d'un artefact décolonial car il préconise de déconstruire, à travers le choix d'une langue autre, l'ethos hispanique colonialiste/christianisant et d'expulsion. En relation avec les mécanismes métalinguistiques identifiés lors de la publication de la poésie néo-djudezme et en comparaison avec la proposition de Gelman de lecture interstitielle, l'article évalue le concept de « textes dupliqués » suggéré par J. Walsh Hokenson et M. Munson lors de leurs réflexions sur les littératures bilingues et puis examine les manifestations translinguistiques des textes, en vérifiant ses effets sur la divergence de genre qu'ils soulèvent. Enfin, l'étude postule qu'en résistant à la modernité, dans sa dissidence, la poésie néo-djudezme produit une avant-garde poétique.

Mots clés : Judéo-espagnol; néo-djudezme; poésie latino-américaine; autotraduction; Denise León; Juan Gelman; Myriam Moscona.

\section{Neo-djudezmo in the Latin-American Dissident Poetry: The Construction of Interstitial Registers Between Self-Translation and Glossaries}

\begin{abstract}
In the background of the extermination of species and cultures characteristic of the Anthropocene-Capitalocene and, among them, that of the Sephardic culture during the Shoah, the article wonders about the announced agony of the Judeo-Spanish language and the end of an era of native minor languages. It addresses the field of the new djudezmo poetry in Latin America, as well as the role played by metalinguistic devices such as self-translation and the glossary in the process of its production. The article focuses on the case studies Poemas de Estambul (2008) and El saco de Douglas (2011) by Denise León (Argentina), and Ansina (2015) by Myriam Moscona (Mexico). The poetry collection Dibaxu (1994) by Juan Gelman is identified not only as the main hypotext of these works but also as an epistemic event - an intertextual producer of new knowledge - in Ibero-American literature that plays the role of a decolonial artifact because it advocates to revisit, through the choice of 'the language of otherness', the Hispanic colonialist/Christianizing and expulsionist ethos. In relation to the metalinguistic mechanisms identified when publishing poetry in neo-Djudezmo and in comparison with Gelman's proposal of interstitial reading, the article evaluates the concept of "twinned texts" suggested by J. Walsh Hokenson and M. Munson when thinking about bilingual literatures. It then examines the translinguistic manifestations of these texts, verifying its effects on the gender divergence they raise. Finally, it postulates that, by resisting modernity, through its dissidence, poetry in neo-Djudezmo produces a poetic avant-garde.
\end{abstract}

Keywords: Judeo-Spanish; Neo-Djudezmo; Latin American poetry; self-translation; Denise León; Juan Gelman; Myriam Moscona; 
Lo que cada palabra en una lengua arrastra, calla y dice y vuelve a callar está unido a una constelación de silencios y decires de todas las palabras de esa lengua, unido con lazos de fuego azul que iluminan tenuemente su noche, resplandecen de pronto y vuelven a callar, no a apagarse, ondulantes como acero líquido cuyo fulgor es anuncio de firmeza que fuera cimiento del gran todo de una lengua Gelman (1992, p. 83)

\section{Introducción}

Todo neologismo formula un enunciado político porque pide enfrentarse a una postura glotopolítica para repensar la vigencia de esta en el tiempo. Si propongo los términos "poesía en neodjudezmo" para analizar una lírica en una lengua que tal vez tenga más nombres que criaturas que la aprenden -ladino, spanyolit, (d)judezmo, djidyó, español arcaico, judeoespañol, sefardí, haketía (en Noráfrica), espanyol muestro, etc. (Bunis, 2017) - , es porque considero que la reciente e incipiente literatura en judeoespañol en América Latina marca un hito histórico, filológico y político que merece atención distintiva. Por esta razón, y para insistir en la novedad del fenómeno, opto por el término (neo)djudezmo, ${ }^{2}$ utilizado en menor medida que los de "ladino" y "judeoespañol", por cuanto es específico, resalta el carácter transnacional judío (tan característico de esta lengua), evidencia la mirada occidental que vincula al judeoespañol con la subalternidad y destaca, por ende, su diferencia y el rol de otredad atribuido en el entramado lingüístico de Occidente.

E1 fenómeno de poesía en neodjudezmo sucede a contrapelo del consenso que reconoce la agonía del judeoespañol y pone en duda la capacidad superadora de cualquier manifestación viva que se oponga a dicho consenso. Si bien adhiero a la incontestable y crítica con-

2 Según Salvador Santo Puche, se utiliza el concepto de neoladino para describir, en la actualidad, un uso "hiperhispanizado" del judeoespañol (Pascual, 2008, p. 151). Mi propuesta difiere y complejiza esta situación en textos de ficción y poesía. dición existencial del judeoespañol, considero que debe contextualizarse en relación histórica con el antropoceno (también llamado "capitaloceno") (Steffen et al., 2015).

Entre otras cosas, sería importante pensar reflexivamente el lugar desde el cual hablan los y las filólogos/as hispanistas y las y los historiadoras/es culturales (y me incluyo), quienes, desde un espacio apocalíptico - nuestro siglo XXI-, reconocen el fin de las cosas en los objetos que estudian, a distancia, pero no observan la relación entre aquellos objetos y sujetos, y sus propias voces. Dadas las circunstancias en las que cada dos semanas muere una lengua arrasada por historias violentas y regímenes de odio, se desdoblan los mares en tsunamis y arremeten pandemias, caeríamos en falta si no relacionáramos la agonía del judeoespañol con la desaparición de una era.

Si la Modernidad se definió a partir del viaje transatlántico, el descubrimiento de la crueldad occidental sobre el cuerpo de las otras y los otros, y el racionalismo y su ciencia, debemos identificar la estrecha relación entre la cadena aparentemente imparable de la masiva destrucción biológica característica del antropoceno, la globalización tecnológica, económica y social, y la aniquilación de las culturas en sus diferencias (sus pueblos, sus voces, sus lenguas). La Shoá (1939-1945) también debe leerse en este contexto, producto extremo de la era de la crueldad moderna: es allí precisamente donde se dio el golpe fatídico a la lengua judeoespañola, masacrando al $90 \%$ de sus hablantes nativas y nativos (Della Pergola y Schmelz, 2006), mujeres y hombres sefardíes que en su gran mayoría residían en Grecia, Turquía, Francia, Noráfrica y los Balcanes (Díaz-Mas, 1986).

¿Qué rol jugaría entonces, 60-70 años más tarde, una nueva lírica en una lengua agonizante? El oxímoron que opone la vida a la muerte no debe leerse si no como forma de resistencia. Si bien el mundo, tal como lo conocemos, desaparecerá, no habrá muerto el judeoespañol, 
pero probablemente definiremos el concepto de hablante de otros modos: será testigo, mensajera, portador o semilla en busca de futuras tierras y lenguas fértiles.

¿Qué dice en este contexto apocalíptico la poesía en neodjudezmo? ¿Qué rol desempeñan sus mecanismos metalingüísticos $\mathrm{y}$, en particular, la recurrente estrategia de la autotraducción? ¿Cuáles son las características de estos mecanismos, qué aportan y qué restan al judeoespañol? El artículo busca modos de dar respuestas a estas preguntas y también propone pensar esta literatura menor, como un David frente a Goliat, o, mejor dicho, una Miriam subvirtiendo la ley fatídica del faraón, en acto sororo y transversal con la hija del palacio.

En el marco de mis investigaciones en estudios judíos y en torno a la literatura políglota (Gabbay, 2020a) y la autotraducción (Gabbay, en prensa), trabajo entonces, en este texto, las obras Poemas de Estambul (2008) y El saco de Douglas (2011) de Denise León (Argentina), y Ansina (2015) de Myriam Moscona (México). Amplío, asimismo, el alcance del epígrafe de Juan Gelman a este artículo, para explorar la relación intersticial que el mismo autor identifica en Dibaxu (1994), dando a entender que las diferencias entre el judeoespañol y el castellano son el espejo donde reverbera el poder de su alianza. Asimismo, defino una serie de eventos epistémicos que, a mi modo de ver, marcaron el rumbo de la poesía latinoamericana en neodjudezmo.

Las obras de León y Moscona, no obstante, no son representativas de un fenómeno numeroso de la poesía latinoamericana; por el contrario, son únicas en su especie. Empero, emergen dentro del marco de un fenómeno cultural transnacional creciente, que se manifiesta en diversos ámbitos: el literario, ${ }^{3}$ el

3 Dice Salvador Santa Puche, en una mesa redonda junto a Margalit Matitiahu, Ángel Berenguer y Benno Aladjem, y coordinada por José Antonio Pascual: "el judeoespañol es una lengua que siempre musical (Balbuena, 2012), el pedagógico, el archivístico y de investigación, el de divulgación transnacional y el de la escritura periodística, así como el de la escritura digital y la creación de foros de hablantes y estudiantes del judeoespañol (Harris, 2011).

Y, sin embargo, observadas desde una óptica transversal, las obras de León y de Moscona son representativas de otro fenómeno literario mundial que ha dado centralidad a la traducción de "lenguas menores" (Casanova, 2008), es decir, subalternas dentro del sistema literario mundial.

La particularidad de estas obras reside en que los mecanismos metalingüísticos utilizados y, en el caso de la obra de León, las autotraducciones, son incorporados como ingredientes poéticos, es decir, cumplen un rol semiótico y estructural dentro de las mismas obras, que desdoblan y multiplican; no es posible deslindarlos de ellas.

\section{El judeoespañol y su literatura}

Desde la Baja Edad Media (siglos XIV y xv) y antes de la conformación de la koiné judeoespañola en el siglo XVI (Minervini, 2002), la cultura gráfica sefardí en España era reconocida, entre otros fenómenos, por su literatura aljamiada (transcripta en el alefato hebreo o árabe) $\mathrm{y}$, en sentido inverso, por sus traducciones calco del hebreo al ladino, tradición que continuó en la diáspora sefardí tras el edicto de expulsión de 1492.

sorprende. Para mí hay un dato muy curioso, una auténtica paradoja. Por ejemplo, si establecemos un gráfico de hablantes del judeoespañol desde el fin de la segunda guerra mundial [sic] hasta nuestros días, tendremos una línea descendente [esto en realidad es incorrecto en lo que respecta a las primeras décadas], pero si establecemos un gráfico del número de libros publicados en judeoespañol o neoladino, tenemos el efecto contrario: a pesar de los altibajos, tenemos una línea ascendente, sobre todo a partir de los años 90" (Pascual, 2008, p. 152). 
La traducción-calco, producto de un ejercicio oral que se practicaba en circunstancias pedagógicas, calcaba la estructura sintáctica del texto hebreo original, traduciendo palabra por palabra vocablos y raíces semíticas al castellano. Al ponerla por escrito, se trocaba el alefato hebreo por el romano, dando por resultado un "texto como descompuesto en una yuxtaposición de microtextos" (Hassán, 2004, pp. 90). A ello se le llamaba "ladinar". Al incorporar también hebraísmos, producía así una versión lingüística que se diferenciaba de cualquier otro corpus ibérico.

El judeoespañol calco o ladino se manifestaba, entonces, como un código lingüístico que podía jactarse, si se quiere, de preservar, a través de la forma, la santidad hebrea en idioma castellano. Ejemplos singulares de traducciones al ladino son el Pentateuco de Constantinopla (1547) y la Biblia de Ferrara (1553).

El ladino (de alfabeto romano), por lo tanto, sentó las bases, en la Baja Edad Media, para un judeoespañol exílico y transnacional aljamiado. ${ }^{4}$ Si bien de esto podría establecerse que el ladino y el judeoespañol son dos lenguas diferentes (Alvar, 2000, pp. 19-35; Vidal Sephiha, 1994), adhiero, sin embargo, a Iacob M. Hassán, quien los identifica como la misma lengua en momentos de conformación y evolución distinguibles (2004). Téngase en cuenta que hoy en día se utiliza popularmente el término "ladino" para referirse al judeoespañol vernacular. ${ }^{5}$

El consenso histórico determina que el judeoespañol se distinguió de las lenguas peninsulares durante el siglo XVI, aunque existen discordancias en cuanto a su cronología (Borovaya, 2017). Si bien la expulsión de la población

4 Dependiendo de las comunidades, en los Balcanes, por ejemplo, el judeoespañol local utilizó también el alfabeto cirílico, y en Grecia, se mostró funcional el alfabeto griego.

5 Para prevenir confusiones evito, en mi análisis, el uso del término "ladino". sefardí de España había sido dictada en 1492, y la de Portugal en 1497, las y los súbditos expulsada/os de estas Coronas cristianas continuaron hablando las lenguas peninsulares durante generaciones.

Respecto al castellano, en particular, y así como era el caso de las otras lenguas ibéricas, en el momento de la expulsión, la lengua todavía no había pasado por el cedazo de la normativa académica. De hecho, la Gramática castellana de Antonio de Nebrija fue publicada el mismo año del edicto. Si bien este volumen no había sido el primero en regular un orden lingüístico que fuera funcional al poder homogeneizante de la Corona, fue a partir de ese evento metalingüístico de suma importancia que el castellano peninsular fijó sus normas y alfabeto único. Las y los sefardíes, entonces, no se llevaron consigo el español regulado (ni tampoco el portugués, con una primera gramática fechada en 1532) que utilizó el Siglo de Oro.

La progresiva conformación del judeoespañol que toma como base el español "arcaico" y otras lenguas ibéricas - pregramaticales-, en particular el portugués, el gallego, el leonés, el aragonés y el catalán (Attig, 2012, pp. 832, 836), varía según el espacio geográfico donde se asentaron las nuevas comunidades sefardíes. Al léxico y a la gramática peninsular se agregaban vocablos, expresiones y estructuras locales. Por esta razón, el judeoespañol que se desarrolló bajo el Imperio otomano recoge una multiplicidad de vocablos y modismos turcos que portan, asimismo, la idiosincrasia cultural del país (Quintana Rodríguez, 2011). De este modo, no es definible un judeoespañol "único", sino una

6 Respecto de los supuestos arcaísmos en judeoespañol, Aitor García Moreno aclara que "El mantenimiento en judeoespañol de formas propias del español preclásico, alcanza su máxima expresión en la fonética y en menor medida en el léxico. En el ámbito de la morfología y la sintaxis, por el contrario, son más bien escasas las características conservadas en judeoespañol que hayan sido desechadas por el estándar peninsular" (2006, p. 44). 
koiné, con una diversidad de variantes y un alto grado de polimorfismos.

Fue en 1928, con la reforma nacionalista-laicista de Mustafá Kemal Atatürk, que el judeoespañol, en el Imperio otomano, trocó su alefato por el alfabeto romano. Esta imposición, que afectó a la literatura y el periodismo sefardí local, terminó desencadenando una "conversión escritural" generalizada en otras geografías. Sin embargo, la escritura hebrea impresa Rashi, así como la manuscrita solitreo, si bien excepcionales, no desaparecieron del todo.

Hasta 1938, antes de la Shoá, las comunidades sefardíes contaban con una población mundial de unos 350 mil miembros. Tras la masacre, sobrevivieron solamente 50 mil mujeres y hombres sefardíes. En parte, esto fue posible gracias a la temprana migración sefardí a Medio Oriente tras el edicto de expulsión y a partir de fines del siglo XIX a tierras americanas, aunque la presencia de comunidades sefardíes (abiertas o criptojudías) en América Latina se remonta al siglo $\mathrm{xv}$ (Bernardini y Fiering, 2001). Dichas comunidades, en su mayoría de judeo-conversos, fueron perseguidas y amenazadas hasta su casi total destrucción o asimilación. Las comunidades sefardíes latinoamericanas de hoy se deben entonces fundamentalmente a la migración masiva de Europa, Magreb y Medio Oriente, iniciada a fines del siglo XIX. A estas se agregaron los y las sobrevivientes sefardíes de la Shoá, que llegaron durante la Segunda Guerra Mundial o ya después de 1945 (Avni, 2003, pp. 17-33).

Aun así, la comunidad investigadora no se pone de acuerdo a la hora de contabilizar a los y las hablantes del judeoespañol. Las estimaciones que incluyen, hoy en día, tanto a América Latina como a América del Norte, el Caribe, Francia, Noráfrica, Turquía, los Balcanes e Israel estipulan un número que varía entre 200 mil (Balbuena, 2016, p. 8) y 11 mil hablantes nativos y nativas (Harris, 2011, p. 58). En su gran mayoría, se trata de abuela/os y bisabuela/os y sus descendientes directa/os, quienes, si bien reconocen la lengua sefardí, no la utilizan fuera del vínculo con sus mayores. ${ }^{7}$

Es en este contexto en el que se crea una nueva literatura judeoespañola que en América Latina está intrínsecamente relacionada con las prácticas de traducción y con la poesía, aunque, como en otras geografías, también ofrece textos narrativos. Sin embargo, haciendo honor a la historia de la literatura judeoespañola, cada una de estas prácticas es sumamente singular y el judeoespañol que producen no sólo incorpora variantes pasadas particulares, sino que también genera nuevas variantes relacionadas con la biografía familiar de las escritoras - siendo los escritores varones una minoría-, sus circunstancias, geografías y sus poéticas.

Mi propuesta, que presenta la nueva poesía judeoespañola en América Latina como poesía en neodjudezmo, focaliza su interés en sus tópicos, sus prácticas intertextuales y la centralidad del género, que se inscribe en las voces emisoras y representadas por dicha literatura. Asimismo, subraya la relación paradójica, simbiótica y a la vez históricamente reparadora con el castellano local, y es allí donde las prácticas metalingüísticas que acompañan los textos en judeoespañol, entre ellas, la autotraducción y la construcción de glosarios, se tornan definitorias.

Aquí es importante mencionar las fuentes literarias y lingüísticas que se encuentran a disposición de quien escribe hoy en día en judeoespañol. Si bien los textos sagrados en ladino (o judeoespañol calco), como, mencionamos, la Biblia de Ferrara y el Pentateuco de

7 El debate en torno al número de hablantes del judeoespañol permanece indecidible. No sólo porque el número decae dramáticamente día a día, sino porque resulta metodológicamente complejo definir el propio concepto de hablantes en una situación de crisis, transnacional, y que requiere la, de por sí, difícil tarea de documentar la cultura oral (Refael, 2020b). 
Constantinopla, representan fuentes significativas del siglo XVI, y el comentario bíblico $M e^{\prime} a m$ Lo'ez del siglo XVIII (a partir de 1730 en Turquía) es una obra fundamental del judeoespañol, sus modos están apegados al lenguaje y a la estructura bíblica y erudita. Además, la cultura sefardí se caracteriza por una interesante tradición del romancero (Armistead y Silverman, 1982; Díaz-Mas, 1994).

Por otra parte, el judeoespañol supo actualizarse a lo largo de la historia, al incorporar y producir nuevos y modernos vocablos a su corpus lingüístico, lo cual contribuyó a que se conformaran variantes diferenciadas de la lengua, con base en las mencionadas lenguas pregramaticales, sumando a los dialectos locales vocabulario francés, turco, hebreo, árabe, griego e italiano.

Textos modernos, muy relacionados con el periodismo en judeoespañol, ofrecen un despliegue de la lengua en su proceso de actualización (que, empero, propongo no llamar "modernización", puesto que sus hablantes se oponen a acatar normas académicas rígidas, y en este sentido se trata de una lengua desobediente que reconoce el valor de su pluralidad). En efecto, la prensa sefardí produjo, a lo largo de su historia, unos 300 periódicos en sus diversas comunidades (Asuero y Gerson Sarhon, 2007). $\mathrm{Su}$ época de apogeo tuvo lugar entre finales del siglo XIX y la Segunda Guerra Mundial. La prensa sirvió, asimismo, como plataforma para la publicación de traducciones de literatura mundial, como, por ejemplo, algunos capítulos de el Quijote, publicados en Turquía en 1881 y 1931 (Sánchez-Pérez, 2019), entre otros títulos. $^{8}$

Hoy en día, los periódicos existentes son, desde 1979, Aki Yerushalayim (en Israel), ${ }^{9}$ con una tirada de 1 a 3 veces por año, y el suplemento mensual El Amaneser ${ }^{10}$ que, desde 2005, lleva

8 Otros capítulos de Don Kishot aparecieron más recientemente, en el número 86 de Aki Yerushalaim entre otras fuentes.

9 Véase Aki Yerushalayim (2021).

10 Véase El Amaneser (2005-2021) el lema "Kuando muncho eskurese es para amaneser", del semanario de Estambul Shalom - publicado enteramente en judeoespañol hasta 1983-. Demás está decir que los y las colaboradores/as de esta prensa provienen de diversas comunidades sefardíes del mundo. También es fundamental el intercambio que está ocurriendo entre hablantes y exploradoras/es del judeoespañol en la plataforma de internet Ladinokomunita (s. f.).

Actualmente, hay una diversidad de proyectos relacionados con el judeoespañol que niegan de manera contundente que este registro sea "posvernacular", puesto que está en boca de munchos y munchas que buscan resistir a la extinción de la lengua propia. Sin duda, la tecnología ha jugado un rol central en la difusión del judeoespañol y en la reanimación y la cooperación de las comunidades judeoespañol-parlantes. ${ }^{11}$

En el ámbito filológico, es preciso destacar, más allá de una diversidad de glosarios que pueden encontrarse en bibliotecas y en línea, los dos diccionarios más importantes que posee al día de hoy el judeoespañol: 1) el Dictionnaire du Judéo-Espagnol de Joseph Nehama (2003 [1977]) define y explica en francés lemas del djudezmo. Si bien está incompleto, aporta más de 20000 entradas, que incluyen definiciones situacionales y expresiones idiomáticas de Salónica, y recuperan el uso del judeoespañol en circunstancias tradicionales y modernas (Bunis, 2011). El modo de transcripción optado es, no obstante, singular (Mancheva, 2014). 2) El Diksionario Ladino-Ebreo, Ebreo-Ladino de Matilda Koén Sarano (2009), que cuenta con 50000 entradas.

11 El Centro Cultural Sefarad de Buenos Aires, fundado en 2008, ha sabido aprovechar con elocuencia el espacio digital y mantiene una incansable plataforma, llamada eSefarad, que concentra eventos transnacionales a diario. Véase eSefarad (2008-2022). 
Por último, un recurso que continúa en proceso de desarrollo y que destaca por su envergadura es el Diccionario histórico del judeoespañol, proyecto en línea dirigido en el Consejo Superior de Investigaciones Científicas español por Aitor García Moreno desde 2013. ${ }^{12}$

En relación con la literatura contemporánea que puede servir como fuente lingüística y modelo de género literario a seguir, los casos más reconocidos son los de Clarisse Nicoïdski, Lus ojus, las manus, la boca (1978), y la larga carta de Marcel Cohen a Antonio Saura, Letras a un pintor ke kreya azer retratos imaginarios: por un Sefardi de Turkia ke se akodra perfektamente de kada uno de sus modeles (1985). Estos dos textos son de interés para nuestro trabajo, porque fueron ellos los que fundaron la práctica de la traducción y las ediciones bilingües para proveer a los textos judeoespañoles contemporáneos de mediaciones metalingüísticas. ${ }^{13}$

Cohen y Nicoïdski, francés y francesa sefardíes, habían obtenido renombre con anterioridad por sus obras francófonas y publicaron textos en judeoespañol en un momento avanzado de sus carreras. En el caso de Nicoïdski - autora de origen bosnio e italiano-, el poema fue publicado de modo bilingüe, acompañado por una traducción al inglés por Kevin Power (Cassani, 2019a, pp. 5-22). ${ }^{14}$ La carta

12 Hay diversos proyectos que trabajan actualmente en pos de la construcción de diccionarios del judeoespañol. Uno de ellos es el Muevo diksionario digital del ladino, en construcción, en el marco de WordReference (https://www.wordreference. $\mathrm{com} /$ ).

13 Aquí debe agregarse el poemario y la autotraducción al hebreo de Siniza y fumo, de Avner Pérez (1986). Diez años más tarde apareció, en Israel, una traducción al inglés (Pérez, 1996).

14 Si no fuera porque Céline Piser cita a Kevin Power en su tesis de doctorado, y el hijo de Clarisse, Élie Robert-Nicoud, da más detalles en su memoria genealógica, Irremplaçables (2019, pp. 118-120), dado que el copyright del libro está adjudicado únicamente a la autora Clarisse Nicoïdski en el peritexto de la segunda página, me preguntaría de Cohen es publicada en judeoespañol y sólo años después el autor produjo una autotraducción del texto que había dirigido originalmente a Antonio Saura. Alessia Cassani analiza con precisión el modo en que Cohen manipula la autotraducción mediante la corrección y adaptación de la versión francesa a los requerimientos del público francés (2019b, pp. 23-40).

Considero que estos dos textos funcionan, en el sistema histórico-literario de las literaturas del mundo, como lo que denomino "eventos epistémicos", es decir, hitos literarios que se manifiestan como intensos y particulares productores intertextuales de un nuevo saber. Estos dos eventos epistémicos suceden a contrapelo de la globalización capitalista del antropoceno (Bonneuil y Fressoz, 2013), y 35-40 años después de que uno de sus eventos más devastadores amenazara verdaderamente con acabar con la cultura sefardí. Es absolutamente necesario reconocer la relación activa entre el evento catastrófico de la Shoá y estos eventos epistémicos que, por un lado, llaman la atención hacia la herida histórica abierta de Europa y, por otro, instalan la posibilidad de reconstruir, mediante el lenguaje - aunque sea imposible recuperar-, un mundo perdido.

En 1989, la escritora hispano-mexicana Angelina Muñiz-Huberman reunió una diversidad de obras en La lengua florida. Antología sefardí, instalando por primera vez en América Latina un espacio para el judeoespañol.

Finalmente, otras autoras y otros autores contemporáneas/os que escriben en judeoespañol pueden desempeñar el rol de interlocutoras/ es o intertextos literarios. Ellas y ellos son, por ejemplo, Margalit Matitiahu (Israel), Avner Pérez (Israel), Rosa Nissán (México) —quien

\footnotetext{
si "Kevin Power" no sería un heterónimo de la autora, o bien un sustituto autoral/traductor, y de ese modo su traducción al inglés - que aparece respectivamente junto a los poemas en judeoespañol y de la que Nicoïdski fue experta profesora- debería ser tratada de hecho como autotraducción.
} 
intercala, como luego lo hizo Myriam Moscona en Tela de sevoya (2014 [2012]), el castellano mexicano con el judeoespañol-, Matilda Koén Sarano (Italia-Israel), Matilda Gini de Barnatan y Viviana Rajel Barnatan (Argentina-España) y Eliezer Papo (Serbia-Israel) (Moscona y Sefamí, 2013). Además, autores como Arnau Pons, Gladys Pimienta, Avner Pérez, Rachel Amado Bortnick y Carlos Levy se han dedicado a la traducción al judeoespañol, aun cuando algunas/os de ellas y ellos no escriban su propia obra en dicha lengua.

\section{El evento epistémico de la poesía en neodjudezmo}

Sin embargo, los textos de Nicoïdski y de Cohen no representan, en América Latina - tierra de los refugiados y las refugiadas de Europa-, lo que significan en el Viejo Continente. Escribir en judeoespañol en Europa implicó reivindicar la existencia y vigencia de una Europa también judía, a pesar y a contrapelo del genocidio perpetrado. Sin embargo, el evento epistémico relacionado con el judeoespañol en América Latina es el poemario $D i$ baxu de Juan Gelman (1994).

Gelman, poeta y exiliado político, revela, en su "Escolio" a Dibaxu [Debajo] (1994, p. 5), que compuso poemas en judeoespañol "entre 1983 y 1985 ", de modo que se sobrentiende - por la cronología y el peritexto: "A Aurora Bernárdez/Quien además me introdujo en la poesía de Clarisse Nicoïdski, diáfana como un fuego"- que el hipotexto fundamental de Dibaxu es el texto Lus ojus, las manus, la boca. Esto también es relevante, ya que la variedad del djudezmo adoptada por Gelman es la que aprendió de Nicoïdski, el judeoespañol bosnio, que tiene su marca diferencial en las terminaciones en $[\mathrm{u}]$ —como en "ojus" y "manus".

Sin embargo, Gelman (1994) explica también el origen intratextual de su opción judeoespañola, que posiciona en relación directa con sus Citas y comentarios, obra contemporánea al libro de la poeta franco-sefardí, pero publicada en 1982, y dedicada a pensar desde la poesía mística de los poetas de origen judeoconverso Teresa de Jesús y Juan de la Cruz. Es decir, Gelman resalta $(1994$, p. 5) que si bien los poemas de Nicoïdski "desvelaron esa necesidad" de conectarse con el djudezmo que él luego comprendió como necesidad "dispuesta a despertar", su relación con el judeoespañol se encontraba de hecho latente, puesto que formaba parte de su deseo de iluminar "las raíces en la lengua", raíces que buscó en el marco de su situación de exilio.

A esta nota debemos agregar - aunque Gelman prescinda de ellos - los textos hebreos y aquellos específicamente sefardíes de Gelman en Interrupciones II, específicamente en el apartado "Composiciones", donde traduce y reformula las voces judías de envergadura, pero también encarna un personaje-poeta sefardí subrepticiamente infiltrado al que nombra "Eliezer Ben Jonon" (Gabbay, 2006, pp. 109-120).

Si bien Gelman lee a Nicoïdski en Europa y escribe en judeoespañol en el mismo continente, su función como poeta latinoamericano y argentino resignifican su relación con el judeoespañol y lo instalan en el contexto español y latinoamericano, de modo que Gelman se convierte en mediador entre Europa y Latinoamérica, pero también entre la literatura judeo-europea y la judeo-latinoamericana. Esta mediación, producida de la mano de Dibaxu, se materializa a través de su autotraducción al castellano.

Aquí es de importancia destacar que Gelman va más allá de Nicoïdski y de Cohen, porque interpela a sus interlocutores e interlocutoras mediante "instrucciones de uso", por un lado, solicitando el retorno a la lectura en voz alta y, por otro - y esto es fundamental-, instalando la significancia de su poema en el espacio intersticial que nosotras/os lectoras/es descubriremos eventualmente en la lectura oral sucesiva de la versión judeoespañola y la castellana de Dibaxu. De modo particular, el autor reconoce a estas dos lenguas como dos castellanos: 
[...] ruego que los lea en voz alta en un castellano y en el otro para escuchar, tal vez, entre los dos sonidos, algo del tiempo que tiembla y que nos da pasado desde el Cid (Gelman, 1994, p. 5, el resaltado es mío).

En particular, rescato la idea de los dos castellanos yuxtapuestos en el poemario mediante una anunciada autotraducción. En este sentido, Jan Walsh Hokenson y Marcella Munson caracterizaron el texto literario bilingüe y su autotraducción como twinned (2007, p. 2) traducible como "agemelado"/hermanado/ emparejado-, palabra que en inglés lleva connotaciones relacionadas con la especularidad que reverbera sin término entre dos cristales. Sin embargo, más adelante aclaran: "The bilingual text [en este caso la autotraducción] is never merely twinned, in a mirror version, because style is irreducibly both linguistic and literary" (p. 174).

Además, si los espejos difieren en textura y ángulo, la reverberación modificará la imagen hasta deformarla. Las lenguas mellizas - no así las gemelas - no representarían una duplicación, sino la manifestación de divergencias, producto de la diversidad de contextos espaciales y temporales en los que se desarrolla el castellano - por ejemplo, difieren el lenguaje de Nicomedes Santa Cruz y de Roberto Goyeneche-.

Al establecer el rango de "castellano" para el judeoespañol, en conjunto con el español, Gelman realizó una operación antijerárquica, restableciendo la dignidad — manchada por la expulsión y luego la Shoá- de la judeolengua.

$\mathrm{Si}$, por el contrario, tomamos la idea de twinned como especularidad y refracción, entonces podemos concentrarnos en la concepción revolucionaria de Gelman, que consiste en sentir, de manera simultánea, ambos castellanos en el espacio intersticial que los aparta y une a la vez ${ }^{15}$ en un juego de espejos, de transferencias,

15 Insistimos en que el judeoespañol no es mero castellano, sino una lengua con historia propia y de migración sensual (también "hacia el porvenir", destaca Fabry, 2001, p. 99). Y esto sucede precisamente porque el lector y la lectora modelo de Dibaxu no son los y las djudezmo-hablantes, sino las y los hispanohablantes que "olvidaron" la existencia y la persistencia del judeoespañol.

Dibaxu es, entonces, una interpelación a los estratos profundos de la memoria, aquella a la que no se puede acceder sin atravesar las capas históricas y lingüísticas del olvido - un espacio, un magma, por cierto, permeable-, sin, de hecho, reconocer la existencia de una oquedad instalada en nuestro lenguaje y compuesta de significancias sin significantes visibles. Dibaxu es también una interpelación a los estratos profundos de la conciencia y la responsabilidad histórica, ética y política.

En Latinoamérica y en particular en Argentina, Dibaxu adquiere un estatus decolonial en discordancia con su aporte al fenómeno literario identificado por la crítica como neosefaradismo (Aizenberg, 1982; Elkin, 1995), un fenómeno que tuvo tempranas manifestaciones a comienzos del siglo xx y que consistió en la identificación de autores de origen asquenazí (Alberto Gerchunoff, Carlos M. Grünberg o César Tiempo) con la cultura sefardí y su lengua, el djudezmo, mediante lo que denomino una "impostura" en español áureo. ${ }^{16}$ Esta impostura ficcional, adoptada por autores provenientes de la cultura asquenazí, no deja de ser, en términos culturales, una apropiación del legado sefardí, cuestión que la crítica aún no ha tenido en cuenta. Es paradójico - y la paradoja enriquece-, que Dibaxu se reafirme como dispositivo decolonial frente al español

diferenciada, y con variantes fundadas sobre una diversidad de lenguas ibéricas, incluidas las occitanas. Rescatamos, sin embargo, el parentesco reconocido por Gelman y la relación enigmática que identifica entre ambas lenguas.

16 Desarrollo el concepto de impostura relacionado a otro campo lingüístico en Gabbay (en prensa). 
colonizador, a pesar de ejercer una apropiación cultural.

En el marco de la construcción del crisol de razas en Argentina, el neosefaradismo en la literatura vehiculizó el reclamo de pertenencia de la cultura judeo-argentina a la cultura nacional, mediante la identificación con el pasado judeo-hispánico. En un movimiento doble por el cual se reclama la pluralidad de la cultura hispánica, revalorizando sus ingredientes no cristianos, el neosefaradismo también incluye, en el concepto de argentinidad, a la cultura judía y, tácitamente, estaría invitando a la incorporación de otras culturas tanto inmigrantes como autóctonas.

El neosefaradismo no es, de ningún modo, el caso de la poesía que denomino "en neodjudezmo", dado que las poéticas de sus autoras sí están intrínsecamente relacionadas con los contextos lingüístico-culturales de su producción. Sin embargo, no es menor la responsabilidad que tuvo el neosefaradismo en visibilizar, mediante dicha impostura, la cultura sefaradí en Latinoamérica. De allí que sea de importancia destacar a Dibaxu como evento epistémico dentro de la historia literaria latinoamericana y responsable, en cierta medida, de legitimar un espacio literario judeoespañol en el continente.

Esto no significa que la literatura judeoespañola no se haya manifestado en América Latina sin relación previa a la obra de Gelman; sin embargo, es notoria la crítica en torno a $D i$ baxu desde su aparición (Foffani, 1995) y en particular ya entrado el siglo XxI (Balbuena, 2009; Fabry, 2001; Romero Sued, 2014), así como una sucesión de publicaciones, música y traducciones al judeoespañol en Latinoamérica (Balbuena, 2016).

Dicho esto, me dedico a continuación a presentar las particularidades de la poesía latinoamericana en neodjudezmo a través de los casos de la poesía de Denise León (Argentina) y Myriam Moscona (México).

\section{La poesía latinoamericana en neodjudezmo: los casos de Denise León y Myriam Moscona}

Si propongo denominar la poesía en judeoespañol, en el siglo xxi latinoamericano, como "poesía en neodjudezmo", es porque su relación con el castellano local es distintiva de las poéticas que produce.

Un fenómeno paralelo había sido identificado por Elena Romero respecto de la literatura sefaradí a mediados del siglo XIX, en lo que visualizó como un proceso de modernización (que yo preferiría denominar "neocolonización") bajo la influencia francófona de la Alliance Israëlite Universelle —una institución internacional judía de corte francófono, que se convirtió en educadora y formadora de las comunidades sefardíes de Europa, Noráfrica y Latinoamérica a partir de 1860 (Szurmuk, 2019)—. Romero, entonces, identificó un cambio cultural sustancial en este contexto y denominó la nueva cultura "neojudeoespañola". Dice:

[...] si bien la literatura de contenido tradicional-religioso no se interrumpe, empieza a convivir con géneros "seculares" de reciente adopción, como son el periodismo, el teatro, la narrativa, la poesía de autor, la historia [...], la biografía, etc. Esta literatura adoptada es mayoritariamente francesa en su inspiración y está expresada en un neojudeoespañol muy evolucionado y distanciado de su secular antecedente hispánico y también de su castizo precedente del siglo XVIII. El tercer hito histórico se plasma en el siglo xx en el que va a producirse el ya imparable declive de la literatura judeoespañola (1992, p. 42).

Si Elena Romero marcó la segunda parte del siglo XIX como un momento de crisis del judeoespañol y de su literatura en Europa, y si bien acertó en identificar el declive que esta crisis significó durante el siglo xx, la aparición de nuevas manifestaciones de la literatura judeoespañola en otro continente, el latinoamericano, en diálogo con las culturas locales, da pie a identificar una renovación de esta literatura y 
que esta renovación en neodjudezmo sea signo de revitalización y no de declive.

Alessia Cassani menciona la paradoja de la resefardización de la cultura judeoespañola en América Latina, a raíz de "la reintegración de sefardíes en sociedades hispanas" (2019c, p. 55) que, "sin embargo, lleva consigo también una 'rehispanización', o sea, el progresivo abandono de la lengua sefardí, a favor del castellano actual, lengua dominante a su alrededor" (p. 56).

\subsection{Poemas de Estambul (2008)}

Argumenta Shmuel Refael Vivante (2010) que la aparición de la figura de la "mujer-poeta" sefardí sucedió a raíz de la poesía escrita por mujeres en torno a los sucesos y la memoria del Holocausto (Lévy, 1989; Refael, 2020a; Refael Vivante, 2008). Hasta entonces, las mujeres sefardíes, dentro de sus comunidades, estaban aisladas de las tareas escriturales y editoriales, $\mathrm{y}$, sin embargo, cumplían un rol fundamental en transmitir el romancero oral (Díaz-Mas y Martín Ortega, 2016).

En América Latina, no obstante, el fenómeno de la "mujer-poeta" sefardí se hizo esperar más tiempo. ${ }^{17}$ Esto tal vez se deba a que la relación de especularidad entre los dos castellanos (que identifica Gelman) no favorece, en el continente, el desarrollo de una literatura en judeoespañol plenamente identificable como tal. Dice Ricardo Feierstein:

Para aquellos autores de origen sefaradí [...] en cuyas casas se hablaba djudesmo o judeo-español, el hecho de manejar un lenguaje tan similar al de los nuevos países de residencia hizo aparecer un fenómeno de isolalia. La similitud con el castellano americano hizo que en poco tiempo ambos se confundieran y muchos términos de la lengua original pasaron al olvido en apenas una generación.

17 En narrativa, aparece en 1992 el caso de Rosa Nissán, quien publica en México Novia que te vea, y en 1996, Hisho que te nazca, novelas donde introduce el djudezmo junto al castellano-mexicano.
Recién en los últimos veinte años se produjo - en todo el mundo- un movimiento de recuperación de los matices de esa lengua extraviada (2021, p. 53).

A continuación veremos cómo la poeta de origen sefardí, Denise León, nacida en la ciudad de Tucumán en 1974 y autora de literatura crítica tanto como lírica, ${ }^{18}$ destaca en Argentina por su elección de incorporar, en dos de sus poemarios, la estrategia metalingüística de la autotraducción y hace de ella parte integral de su poética.

El poemario bilingüe Poemas de Estambul (2008), un volumen de poemas cortos y verso libre, se divide en dos secciones: "La isla de Alicia" en castellano argentino y "Poemas de Estambul" en djudezmo.

Elisa Martín Ortega (2011) insiste en el rol que, en Poemas de Estambul, juega la nostalgia del mundo judeoespañol perdido - también Cassani (2019c, p. 66) - . Martín Ortega analiza la obra poética de León a través de la teoría que la misma poeta-investigadora propuso para estudiar la literatura de otras escritoras de origen judío. Esta operación, que no carece de riesgo, por un lado, enriquece nuestra lectura intratextual de la obra; pero, por otro, reduce al mínimo el marco interpretativo.

"La isla de Alicia", la primera parte, compuesta de 22 poemas, se subdivide, a su vez, en 2 partes de 8 y 14 poemas, respectivamente. $\mathrm{La}$ segunda parte, "Poemas de Estambul", se compone de 7 poemas en djudezmo, yuxtapuestos a sus autotraducciones al castellano - autotraducción que nuestra lectura supone a falta de cualquier otra indicación y que la autora confirmó en el marco de nuestra entrevista—. ${ }^{19}$

18 Entre ellas, véanse: Templo de pescadores (2013b), Poemas de Middlebury (2014) y Mesa de pájaros (2019). En ensayo: La bistoria de Bruria (2009) y El mundo es un hilo de nombres. Sobre la poesía de José Kozer (2013a).

19 La entrevista virtual tuvo lugar el día 1 de julio de 2021. Mi análisis textual — no así el cultural— no 
La primera parte se introduce con el epígrafe de Sylvia Plath, "mi paisaje es una mano sin líneas", ${ }^{20}$ el cual interpreto como condición vital en la que la hablante del poemario se enfrenta a una gran incertidumbre $-o$ simple constatación de horizontes abiertos - respecto de su identidad pasada así como futura.

La segunda parte está antecedida por el epígrafe de Elizabeth Bishop, "Piensa en el largo viaje a casa", ${ }^{21}$ que parece responder al epígrafe anterior, contradiciéndolo. Acaso, entonces, la segunda parte del poemario invitará a un viaje en la búsqueda o construcción de la identidad de la hablante.

Por último, quiero destacar que el poemario está compuesto por dos partes conectadas y que para interpretar los poemas en djudezmo debemos leerlos en relación con los poemas que le preceden en castellano. En efecto, se trata de un volumen de poesía bilingüe y ello no sólo a raíz de las autotraducciones que incluye.

El poemario divide, aparentemente, el territorio donde instala los poemas, en un espacio denominado la "isla de Alicia", correspondiente a una isla ubicada en el canal de Beagle argentino, y en otro, la ciudad de "Estambul", invisible en cuanto su nombre está totalmente ausente de los poemas. La hablante lírica establece, en el primer poema, una relación especular respecto del espacio anunciado: "En el canal del Beagle / hay una isla / que lleva mi nombre" (p. 11). El "Estambul" anunciado,

se atiene a las declaraciones de las autoras, dado que distingo entre intención de la autora e intencionalidad de los textos; la intencionalidad textual requiere interpretación.

20 El verso hace parte del poema "Mujer sin hijos", del año 1962. Son relevantes respecto del volumen de León también los versos siguientes: "Caminos que formaron un nudo, / El nudo que soy yo misma".

21 El verso pertenece al poema "Cuestiones de viaje". Es de notar que otro de sus versos dice: “ $i E s$ una falta de imaginación lo que hace que vengamos / a lugares imaginados, en lugar de quedarnos en casa?’. por su parte, responde a un espacio geopolítico definido con una historia que lo liga directamente a la lengua que dice los poemas (el judeoespañol que reverbera en la autotraducción al castellano moderno).

Dado que los poemas no se explayan en una descripción detallada de ninguno de los dos espacios, estos se erigen tras un velo (la isla "eleva [...] su fantasma", p. 11) como si fueran heterotopías negativas, yermas ("y comprendo con pesar / que mi corazón es fiel / a una tierra en la que no crece nada", p. 13), o en el caso de Estambul, retrotopías visitables mediante el trabajo de la memoria.

Al menos en el caso de la isla, Alicia guarda distancia respecto del espacio al que alude: la observa desde el continente. En el caso de Estambul, la distancia aparece eliminada ya sea porque la hablante lírica (¿aún Alicia?) se encuentra dentro de dicho espacio: "d'esta sivdad que ronka / onde tu nombre no arrelumbra" (p. 60) o porque la distancia es inconmensurable y, en ese caso, la ciudad nombrada es otra - lejos de Estambul—: "Esta sivdad ke keda leshos de tu sangre / y de la solombra de su sangre" (p. 60).

La sangre, en ambas secciones del poemario, parece representar "la hojarasca, la herencia" (p. 19) recibida mediante la palabra. Flota la fantasía de rechazar dicha herencia: "La evasión imposible: matar la propia sangre en mí" (p. 21). Pero más adelante se impone el saber:
Es una realidad
la sangre.
Pero vacilo en aceptarla
apoyada en un dato menor:
la esperanza de que
- en alguna parte-
habrá un árbol
bajo mi dominio (p. 49).

El "árbol", leído en el campo semántico de sangre, debe interpretarse como árbol genealógico. La hablante lírica negocia aquí la herencia recibida y se declara dispuesta a aceptarla, a condición de que la marca de su propia semilla destine su descendencia, 
bajo su dominio, que no es necesariamente marca de poder, sino de pertenencia a un territorio indefinido "—en alguna parte_- y que estaría oponiéndose a la heterotopía yerma de la isla "en la que no crece nada/nunca" (p. 13). De hecho, "Contemplarla / no despierta la pasión / ni el amor por la tierra. [...] / Blanca, / sólo la habitan / los pájaros" (p. 11). Leo aquí, por lo tanto, un rechazo casi total a la posibilidad de nostalgia del pasado.

Lo que sí se expresa será, en la segunda sección del libro, el "[spanto] de ulvidarte / kada noche / en esta sivdad" (p. 60), porque "Tiembla la memoria" (p. 60). Es, entonces, un trabajo de memoria y de olvido escribir estos poemas. No hay nostalgia en la escritura, sino labor de la memoria.

En la segunda parte del poemario, los poemas llevan el signo de pertenencia "de Estambul" y se suceden imágenes de la chikez, una niñez que la hablante reconstruye en judeoespañol:

\section{La kamaretta de mi madre. \\ La yavedura blanka \\ ke mira a la kamaretta. \\ Los talones de mis pieses \\ ke desean \\ $i$ no ayegan la ventana. \\ El empiezo de todas las kosas (p. 64).}

La autora autotraduce introduciendo una variación en el verso 6 , trocando " $i$ " por "pero": "Los talones de mis pies / que desean / pero no alcanzan la ventana" (p. 65).

Esta autotraducción no explicita, sin embargo, cuál es el poema "original": ¿los poemas en djudezmo o los poemas en castellano? La observación de la maquetación del libro permite ambas interpretaciones, pero no se agota con ninguna de ellas. Podría aludir a que los poemas en castellano son los originales, ya que están ubicados en la serie de hojas a la derecha, al igual que los poemas de la primera parte, en tanto los poemas en djudezmo están presentados en la hoja a la izquierda del libro, todos en bastardilla, a la manera editorial que destaca con dicha tipografía las incrustaciones de palabras extranjeras. ¿Se autotraduce, entonces, León al judeoespañol?

Si adoptáramos esta hipótesis, deberíamos seguir preguntándonos: ¿sería posible que, en la primera parte del poemario, en el lugar donde las páginas de la izquierda permanecen en blanco, lo que se muestra sería la no traducción de los poemas al judeoespañol? ¿Estaríase representando un espacio óquedo, una ausencia? ¿O es que esta ordenación responde tan simple como llanamente a una estrategia editorial hegemónica - resultado homogeneizante del supuesto crisol de razas-, que determina que en Argentina se publican únicamente libros en castellano americano y que, por ello, diciéndolo un poco desde el psicoanálisis, el djudezmo que aparece en bastardilla es en efecto una lengua bastarda olvidada, no reconocida por la Península hasta el siglo xx, pero tampoco por sus herederos poscoloniales en tierra americana?

A la inversa, si leyéramos los poemas en judeoespañol como los "originales", debido a su emplazamiento en la serie de hojas ubicadas a la izquierda, es decir, respetando el fluido de la lectura tradicional románica de izquierda a derecha, deberíamos destacar que la operación metalingüística de la autotraducción al castellano, en donde el djudezmo representaría el pasado ("la sangre", "la herencia") y el castellano americano el presente, se produce de facto un salto directo hacia la edad presente y la adultez, edad en la que se realiza el acto de la traducción. Aquí, el rol principal de la autotraducción no se reduciría a posibilitar la interpretación del texto por quienes son extranjeras/os a la lengua judeoespañola, sino que estaría modificando estructuralmente el poema en djudezmo al intervenir su espacio, su unicidad.

Su interferencia llega incluso a dejar una huella subrepticia en la ortografía del djudezmo, en tanto uno de los consensos de las últimas décadas es la del uso de la letra $k$ para representar el sonido oclusivo velar sordo [c], eliminando de este modo el uso peninsular y americano de 
las letras $c$ y $q u$, cuestión que todo el poemario adopta, a excepción del poema en la página 64, donde dice "La palabra ke quita el miedo" (v.10) y dos veces en el poema de la página 66, "mi cabezal está seco" (v.4).

La interferencia de la ortografía consensuada se contamina, dada la yuxtaposición de las autotraducciones al castellano. Esta contaminación abre ventanas de legibilidad en el judeoespañol para hablantes del castellano, juega simultáneamente a destacar la diferencia y la similitud entre las dos versiones. El efecto modifica tenuemente el judeoespañol, lo hispaniza apenas para instalarlo entre el corpus de lectura latinoamericano.

\subsection{El saco de Douglas (2011)}

Este texto, ganador del segundo premio del Fondo Nacional de las Artes, porta el peritexto "poemas" y manifiesta nuevas formas de autotraducción y contaminación intratextual. Es, sin embargo, un volumen de prosa poética, que yuxtapone el estilo directo y el indirecto libre, y preserva marcas de lenguaje coloquial. ${ }^{22}$

E1 libro está dividido en tres partes: "Luisa, 1914", un texto bilingüe de autotraducción evidente; "Klara, 1939", en castellano (que 1lamaría "intersticial" o de autotraducción invisible, tras el cual suena en sordina el djudezmo, como "el olor del pan, invisible y anónimo, se agita en la memoria como un pájaro vivo, debajo de la piel", p. 34), y "Alegre, 1971", en castellano argentino.

La maquetación del libro llama la atención y se distingue de la de Poemas de Estambul porque la versión del castellano americano y la del judeoespañol, en la primera parte, aparecen en la misma página.

22 Un ejemplo: "La maestra dize antes de un año no se paga nada i tienes ke aprender. A los dos años, te emprestan un molde $i$ lavoras para afuera. [...] un chapeo solo $i$ komes un mes. Digo sí, komo no" (p. 22).
El primer apartado, bilingüe, "Luisa, 1914", lleva un epígrafe de Sholem Aleichem. ${ }^{23}$ Cada página consiste, a grandes rasgos, en un párrafo superior en castellano y un párrafo inferior en judeoespañol. No se utiliza la letra mayúscula al inicio de los párrafos y dado que cada pequeño relato se perfila como una estampa que entremezcla tiempos, la falta de mayúscula sugiere el comienzo recurrente in medias res.

El libro todo es una sucesión de zambullidas en la mar intermitente de la memoria. Esto refuerza la categoría antinarrativa del peritexto mencionado.

Ambas versiones se distinguen claramente, porque la versión en judeoespañol no sólo está enmarcada entre paréntesis, sino que además está presentada en bastardilla. La maquetación impone, entonces, la idea de que, siguiendo el sentido de la lectura desde arriba hacia abajo, el sentido de la traducción es del castellano al judeoespañol. Sin embargo, los paréntesis podrían aludir a lo contrario: el texto judeoespañol está presentado como si estuviera en sordina, como si se escuchara en paralelo a la versión castellana, pero en un registro susurrado. También podría interpretarse que el castellano sirve de portavoz o altavoz del texto judeoespañol original. Estas cuestiones producen en las lectoras y los lectores efectos subjetivos que no me parece necesario definir. Destáquese sí, la variabilidad de posibilidades de lectura. ${ }^{24}$ En ambos casos, empero, la autotraducción restablece el valor fundamental

23 "te ubican desnudo / y te miran a los ojos. / Si tienes los ojos sanos, todo va bien. Si no, te obligan / a volver al lugar de donde vienes. / Me parece que tengo los ojos sanos" (p. 14). El poema pertenece a la novela de 1916, Mótl, el hijo del cantor Peise, donde el autor autoficcionaliza la migración junto a su familia, desde Europa del Este a Nueva York. El texto, por lo tanto, pertenece al mismo universo temático e histórico-temporal que el poema de León.

24 La autora, por su parte, testimonia que, en su obra, las versiones judeoespañolas son siempre las primeras en surgir en el proceso de la escritura. 
del judeoespañol en el poemario. Esto se ve reforzado en las siguientes secciones, ya que, al desaparecer visualmente el espacio que ocupaba en la parte inferior de la hoja, permanece vacío, irremplazable.

Las estampas presentadas en "Luisa, 1914" están recuperadas en primera persona, mediante la voz de una niña de 11 años que pierde a su madre y con esa pérdida se siente morir con ella. La niña rememora la vida juntas: "tengo once anyos $i$ voy acia atrás)" (p. 16). El núcleo del recuerdo menciona la partida de su padre descalzo (sin chapines, pp. 15, 17), huyendo del ejército turco que, en 1914, buscaba enrolarlo en la Primera Guerra Mundial.

La sección sugiere una relación intertextual con Pedro Páramo de Juan Rulfo. La hablante lírica, Luisa, comienza anunciando su propia muerte, aunque a diferencia de en el texto de Rulfo, la muerte de la niña se comprende como metáfora de la inmensidad de su desamparo: "Afuera kantan diez hombres" -en referencia a los diez varones necesarios para crear un minyan y recitar el kadish, la plegaria para los muertos-. Y luego: "Aqui, ai dos muertas." (p. 16). En diversas ocasiones, la niña dice de sí misma "soy un fantasma".

En el caso de Pedro Páramo, sin embargo, la anagnórisis respecto de la muerte de la voz del narrador no es sino tardía. Luisa, por el contrario, tiene conciencia personal de la muerte de su madre, pero también expresa la consciencia histórica de la inminente muerte de su pueblo, lo cual —dada la fecha de la sección "1914"-, implica que la voz ha sido enunciada desde un futuro que va hacia atrás y que puede entreverse en frases del estilo de "Adónde está, de dónde viene esta karta amurchada [marchita], adónde mos ibamos a venir" (p. 22).

Por otra parte, aquí, la niña, igual que Juan Preciado, es enviada por su madre en busca del padre que las abandonó: "Voi a toparlo [encontrarlo]" se repite 5 veces en la página 18.
Ambas madres habían reclamado venganza antes de morir. En tanto la madre en Pedro Páramo dice: "Exígele lo nuestro. Lo que estuvo obligado a darme y nunca me dio..., El olvido en que nos tuvo, mi hijo, cóbraselo caro" (1997, p. 7), Luisa, por su parte, dice: "le prometí a mi madre vengarme de él por ke no es djusto todo lo ke mos izo" (León, 2008, p. 21).

Sin embargo, en la página 24 se agrega la perspectiva judía de la búsqueda del padre descalzo: "Voy a toparlo para ke kuando me muera el haham [sabio] demande el nombre de mi padre y alguno, enguayando [lamentándose en llanto], diga: Luisa ben ${ }^{25}$ León.)". En efecto, el nombre del padre y de la madre y, con ellos, la genealogía, son de suma importancia en el judaísmo; recuperar el nombre del padre permite que, al morir, los dolidos puedan rezar por el alma del muerto. En el caso femenino, se usa para el rezo el nombre de la madre.

Por último, tanto Juan Rulfo como Denise León mencionan el último contacto físico con la madre muerta. Dice Rulfo: "Entonces no pude hacer otra cosa sino decirle que así lo haría, y de tanto decírselo se lo seguí diciendo aun después de que a mis manos les costó trabajo zafarse de sus manos muertas" (1997, p. 7). León, por su parte, relata: "Sus dedos largos soltaron mis dedos: sólo me kedaron las promesas" (p. 15) y luego "Mi madre se me soltó de la mano komo kuando se kitaba las puseras [pulseras]" (p. 16). Esta sensación de partida y separación, al soltarse las manos, los vivos de las muertas, se renueva a lo largo del texto.

25 Dado que Luisa es del género femenino, el texto debería decir "Luisa bat León" [hija de] y no "ben León" [hijo de]. Sin embargo, la "incorrección"en el hebraísmo o divergencia respecto del texto en castellano que anota "hija de León" resulta interesante en el contexto en el que la cuestión de género es central en el libro y cuando de Luisa se dice "Esta debió aber sido varón, no mujer. En la mitad del kamino se le kedó el pito. No salió, dizen. Por ke yo era inteligente". En tanto, se oyen las voces de los niños en la calle "Si la vavá tuviera cucú sería рарй' (р. 23). 
Finalmente, la muerte, territorio donde se instala el poema con sus personajes fallecidos, desaparecidos o fantasmas, hace nicho en la lengua:

(shemá Israel [escucha Israel]. Yo ablo una lingua muerta [...] Shemá Israel. Yo no eskrivo de izkierda a derecha. Yo eskrivo de derecha a izkierda. La lingua se me pega al garguero [garganta] ${ }^{26}$ kada vez ke me alevanto en un kavesal [almohada] ke no es mi kavesal [...] ¿No escucha el Dió a los muertos? Shemá Israel. Yo no agradeshko al Dió por no averme echo esclava, por no averme echo no djudía, por no averme echo muyer [...] Shéma Israel. Todo se acabará conmigo" [...]) (p. 19).

Este fragmento de la primera parte es una joya intertextual litúrgica, en cuanto mixtura el relato de Luisa con tres plegarias diferentes:

1. El "Shemá Israel" (Escucha, Israel), que se recita de modo individual antes de dormir, en circunstancias de desesperación y colectivamente como eslabón de numerosas plegarias en diversos ritos. Si bien alude al pueblo de Israel, el llamado indirectamente interpela a la divinidad.

2. El salmo 137, que reza: "Si me olvidare de ti, oh Jerusalén, pierda mi diestra su destreza. Mi lengua se pegue a mi paladar, si de ti no me acordare [...]". En efecto, el judaísmo ha adoptado como mandamiento ${ }^{27}$ el imperativo doble de no olvidar $y$ de hacer memoria.

26 La expresión del salmo 137 menciona el paladar, no la garganta. De modo que la autora modela su texto en base a las necesidades de su ficción. No descarto que esta divergencia del salmo en hebreo sea vox populi sefardí. En todo caso, considero que representa adecuadamente el fenómeno de divergencias que asumo como poesía en neodjudezmo.

27 En mi artículo "El onceavo mandamiento: memoria del fuego en la literatura judía y feminista de la guerra civil española", ejemplifico, por medio de otro caso de estudio, la centralidad que cumple el rol de la memoria en el judaísmo y
3. La plegaria masculina de la mañana, negada por la condición de mujer "Yo no agrades$h k o "$, en la que, en la versión tradicional, el hombre agradece a Dios haberlo devuelto al mundo de los vivos, agradece sus orificios para poder purificar su cuerpo y agradece también no haberlo hecho mujer.

"Todo se acabará conmigo" cierra de modo circular la "plegaria" que emite Luisa y que había comenzado con: "Yo ablo una lingua muerta". En efecto, hace alusión futura al hecho de ser la última generación capaz de transmitir la lengua sefardí y con esta muerte eventual anuncia el fin de las plegarias y los ritos de su pueblo. La desaparición del judeoespañol en el horizonte lingüístico se torna progresivamente palpable en la desefardización del lenguaje en las siguientes secciones del libro. La ausencia de traducción juega, entonces, un rol fundamental que equivale a la muerte de la lengua.

En el nivel lingüístico, ocurre en la primera parte del libro una mixtura de registros que denota una particularidad diferente a la de Poemas de Estambul y deriva en translingüismo. El texto en judeoespañol fluctúa entre el djudezmo y una expresión bilingüe, en la que el judeoespañol se muestra altamente permeable al castellano, produciendo en ciertos momentos una suerte de djudezmollano - un mestizaje de djudezmo y castellano argentino-. Esta contaminación entre el castellano americano y el judeoespañol es mucho más habitual en este libro que en el anterior, tanto en el nivel ortográfico como en el nivel léxico.

Creo preciso aclarar que hablar de contaminación no conlleva ninguna connotación negativa. Bien lo dice Axel Gasquet:

Il ne faut pas comprendre le métissage comme une simple acception du multiculturalisme, ou encore comme la fusion entre les identités et les cultures. D'après Laplantine

cómo este mandamiento funciona semióticamente en la literatura judeo-latinoamericana (Gabbay, 2020b). 
ce qui caractérise les formes du métissage c'est leur inachèvement ou plutôt la possibilité d'être différemment (2007, p. 12). ${ }^{28}$

En efecto, las lenguas vivas son permeables y no sobrevivirían si no estuvieran en constante proceso de cambio.

Este mestizaje de lenguas sucede también en la absorción de la estructura sintáctica judeoespañola en el texto castellano, en cuanto posibilita el uso del objeto directo al comienzo de la frase. ${ }^{29}$

El método de la traducción calco propia del ladino antes y después de la expulsión se utiliza aquí en la traducción del judeoespañol, "Buen mazal no te deseo" (p. 21), que en la autotraducción se convierte en "Buena suerte no te deseo" (p. 20). La trasposición del objeto directo en castellano resulta lírica, precisamente porque dicha construcción es inusual.

Esta absorción estructural del judeoespañol caracteriza la segunda parte de El saco de Douglas. $\mathrm{Y}$, sin embargo, lo que es importante destacar es el acto de la traducción calco.

La segunda parte, "Klara, 1939", si bien anuncia el nombre del personaje en judeoespañol, está compuesta en castellano y precedida de un epígrafe que traduce la situación intermedia de la segunda generación migrante: "una sola cosa me estaba precisamente prohibida: nacer en el país de mis ancestros". ${ }^{30}$ Luego, la relación se abre con una frase que se convertirá en leitmotiv de la sección: "entonces mi madre escribe: por desgracia vivimos todavía” (p. 29).

La sección se distingue por el estilo de la narración, compuesta de frases más largas y

$28 \mathrm{El}$ autor hace referencia a Métissages de François Laplantine y Alexis Nouss (2001).

29 En judeoespañol, este uso no es condicionante, sino una de sus posibilidades.

30 Del guion de George Perec para el ensayo fílmico documental Récits d'Ellis Island, de Robert Bober, 1979. narrativas, y que incluye referencias intertextuales explícitas mediante el uso de bastardillas y dos notas al final del libro. ${ }^{31}$

El yo poético presenta la voz onírica de una hija que expone la imposibilidad de relatarle su sueño a su madre. Es esta imposibilidad la que promueve el relato de un sueño que imagina un río que se sacude en la memoria y se desdobla en trenes y otras figuras representativas de una concatenación.

Reiteradamente, el relato se topa con el leitmotiv de la madre "por desgracia vivimos todavía". Esto debe entenderse como a pesar del diluvio anunciado, que pesa como una amenaza, representado en el río interminable del sueño poético.

En la p. 38, la quinta vez en la que aparece el leitmotiv, ya no se habla de escritura de la madre, sino de lectura de la hija, bajo una estatua situada en un templo: "Me inclino y leo: por desgracia vivimos todavía", cita que esta vez aparece desamparada del relato materno.

La datación incluida en el poemario, que en la tercera parte indica "Alegre, 1971", sugiere la relación filial entre las tres mujeres, Luisa (hija-madre), Klara (hija-madre) y Alegre (mujer que cuida de un crío); sin embargo, esta filiación podría ser únicamente metafórica.

La relación entre las partes se fundamenta en una progresión del lenguaje que sucede a medida que la lectura fluye: el lenguaje se transforma. Inicia con la introducción del judeoespañol en una prosa altamente lírica, que se narrativiza levemente en la segunda parte, cuando el judeoespañol desaparece de la página. Propongo

31 En la p. 30, el párrafo cierra con un verso de Paulina Vinderman, que es adoptado y naturalizado en el texto de León: "no es fácil hablarle de sueños a mi madre". En la p. 39, un segundo intertexto interrumpe la narración, ocupando toda una página: "Tú construye un arca que yo te mandaré un diluvio", paráfrasis del episodio de Noaj bíblico, de un poema de la poeta gallega Chus Pato. 
denominarlo "castellano intersticial": un castellano dentro del cual late aún el judeoespañol, propuesta a la cual aludía Gelman en Dibaxu.

Finalmente, el volumen se cierra con un texto prosaico, que mediante un movimiento metonímico reúne la simbología de las dos primeras secciones: el fruto de la naranja, el género ambiguo de la niña-hablante, su menstruación temprana (p. 23), la gama del color carmín (rojo, naranja y amarillo), negro y azul, símbolos que transmutan en las figuras del caballo azabache (de "largas crines azules" p. 49), el chocho transpuesto al cuerpo de la cría - palabra polisémica que hace referencia a: 1) nombre popular dado a la leguminosa andina llamada tarwi en quechua, elemento aliado en el poema a la naranja que colorea la tarde de amarillo, tanto al final del relato como en la primera parte, donde la sinestesia "el olor amarillo de la naranja" (p. 16) surge cuando la madre cocina la fruta en la cocina de Esmirna; 2) coloquialismo: "feliz", que redunda en el nombre "Alegre" del subtítulo, y 3) entendido popularmente como sexo femenino/vulva-

El Chocho es también el nombre dado a la cría y a través de la nominación reúne en el cuerpo del niño o niña la simbología recogida a lo largo del libro, un cuerpo que cuando se observa en el espejo - cuerpo que escapa de la mujer que busca calzarlo, así como el padre de la niña escapaba descalzo del imperio turco-, se detiene "absorto, los ojos muy abiertos" (p. 52), pidiendo a las lectoras y los lectores que le ubiquemos en el centro de nuestra observación.

¿Es El Chocho, la cría que balbucea, bisnieto de Luisa, la niña fantasma que habla una lingua muerta? La cría, aún en un estadio en el que no se ha desarrollado la lengua hablada, representa tal vez la muerte de la lengua anunciada por Luisa, pero es también un futuro abierto donde plantar esperanza de palabra. Eskapar, sin embargo, significa, en djudezmo, "acabar". La migración sensual a través de la homofonía escapar/eskapar estaría metoními- camente reconduciéndonos a la voz que decía al final de la plegaria de la primera parte: "Todo se acabará conmigo" (p. 19). Por lo tanto, escapar de la lengua madre derivará en eskapar/ acabar nosotras y nosotros con ella.

Las numerosas posibilidades de lectura de este poemario resultan motoras a la hora de replantear, reactivar y exponer el judeoespañol en tierras americanas, dando lugar, si se quiere, a un neodjudezmo en formas líricas, a las que las tareas de traducción y autotraducción otorgan una fuerza exponencial.

\subsection{Ansina (2015) de Myriam Moscona}

Por el contrario, el volumen poético de Moscona rechaza la práctica de la autotraducción y a la hora de exponer a las y los lectores latinoamericanos al djudezmo, ofrece, con un ethos pedagógico, otros métodos metalingüísticos.

Premiada poeta mexicana de origen búlgaro-sefardí, gracias a la financiación de una beca Guggenheim (2006), Moscona recuperó, entre otras cosas, mediante un viaje, su lengua materna, el judeoespañol. Ha publicado once volúmenes de poesía, entre ellos el más aplaudido, Negro marfil (2006). ${ }^{32}$ Tiene tres obras propias que trabajan con el judeoespañol: la novela-poema bilingüe Tela de sevoya (2014 [2012]), el poemario Ansina (2015) y una obra de prosa inédita, León de Lidia. Además, su labor junto a Jacobo Sefamí en el libro Por mi boka (2013), una suerte de antología del djudezmo, ha dejado una impronta mayor y puede considerarse en sí misma -al igual que su predecesora La lengua florida (Muñiz-Huberman, 1989) - como un evento epistémico para las lectoras y los lectores latinoamericanas/os, que pone en el centro de la publicación la traducción del judeoespañol al castellano.

\footnotetext{
32 Algunos ejemplos son: Último jardín (1983), El árbol de los nombres (1992) y La muerte de la lengua inglesa (2020).
} 
Florinda Goldberg (2013) ha explorado el progresivo descubrimiento de la voz sefardí en la obra anterior a Ansina. Naomi Lindstrom (2017) analiza, en el poemario djudezmo, la voz mística y profética. Darrell Lockhart rescata la particularidad de Ansina en cuanto a la introducción de nuevos registros en la poesía judeoespañola, el de la ciencia, la creación literaria, la sabiduría y el humor, que tiñen la lengua judeoespañola con el lenguaje cotidiano (2018, p. 118).

En el marco de nuestra entrevista, Moscona expresó que Dibaxu había representado para ella un "detonador". Este impartió una "sacudida" a su poesía y le tomó diez años elaborar sus efectos. Dicha sacudida la condujo finalmente a explorar el pasado sefardí de su familia y despertar la lengua latente en su paladar. ${ }^{33}$ La "sacudida" desencadenada por el evento epistémico de Dibaxu consistió precisamente en producir un nuevo saber en lengua judeoespañola.

En efecto, como bien dice Lockhart (2018, p. 118), la particularidad de Ansina, y en ello se diferencia plenamente de Tela de sevoya, una vez reintegrado el pasado a su palabra, es que mira el presente y eso le permite actualizar su lengua y abrir un espacio lúdico

33 La entrevista consistió en dos prolongados encuentros virtuales los días 2 y 5 de julio de 2021 . En dicha ocasión y en anteriores encuentros, la autora relató la impactante historia de haber entrado a vivir en un departamento (202) que se encontraba justamente bajo el piso (302) de Juan Gelman, precisamente un día antes de que el poeta falleciera. Allí compuso parte de los poemas de Ansina. Tres años más tarde, durante el devastador terremoto de Ciudad de México de 2017, el edificio habitado por Gelman primero, y luego por Moscona, sufrió una gran sacudida que lo destinó al desalojo. Antes de su partida, Myriam subió al departamento 302 de Juan Gelman y a modo de grafiti escribió unos versos en las paredes, perpetuando, tal vez, el círculo que representa la unión de sus obras djudezmas en la causa común de la memoria judía. dentro del djudezmo contemporáneo. También Alessia Cassani aduce que esta obra no representa "un repliego nostálgico, en el recuerdo de sus antepasados o en el recurso a un estilo o a temáticas ligadas a la poesía medieval. Al contrario, su estilo es prosaico, desenfadado, coloquial" (2019c, p. 77).

Ansina ("así es") es una colección de poemas en djudezmo que juega a introducir selectas frases en castellano y algunos vocablos en francés y hebreo. El volumen está precedido por un exordio y lo cierra un glosario - de los cuales hablaré en la siguiente sección-, y se divide en cinco partes: "De empolvaduras", "De morideros", "De kreaziones i undimientos", "De sensya" y "De eskrivideros".

El poemario todo está encabezado por el epígrafe de Danilo Kiš, "El hombre mira por la grieta".

La gran mayoría de los poemas están compuestos en djudezmo y pueden leerse de manera independiente unos de otros. Sin embargo, es una poética congruente y enriquecedora la que se eleva a partir de una lectura consecutiva de ellos. Los elementos introducidos en otras lenguas, incluida el castellano, se transcriben, a contrapelo de los poemarios mencionados anteriormente, en bastardilla. Este fenómeno otorga la centralidad al judeoespañol. Los fragmentos en bastardilla, además, no cumplen la función de autotraducción, sino que simplemente introducen el elemento bilingüe en los poemas; sin intermediación ni justificación alguna, conviven varias lenguas.

Hay en Ansina una preocupación especial por la sonoridad de los poemas. Se hace uso de anáforas: "trokar al kojo manko / trokar al manko surdo / trokar al surdo siego" (p. 20), "si la boka / si la avla / si el ojo / si el puerpo" (p. 30), "si plazieras" (p. 48), etc.

Por otra parte, hay un poema que se destaca en particular, debido a su forma prosaica, "la letra beth: el muro ב", dedicado a dar una pequeña lección de mística judía, de kabalá, y 
exponiendo, por ende, la elaborada y barroca dimensión semiótica propia del pensamiento judío: "La letra beth, dize la kabalá, es komo una kaza $^{34}$ kon todos los muros abiertos manko uno. [...] // De la otra banda está el saver vedado" (p. 45).

En este poema, es de notar que dos vocablos aparecen en bastardilla, uno en hebreo - perashá, porción de la Torá leída cada semana-, y otro en castellano - "savras kual es el biervo eternidad ama no konozhes nada de ella". En tanto el vocablo en hebreo es un hebraísmo en judeoespañol, no se conside-ra habitualmente como palabra extranjera. La palabra en castellano, por su parte, podría haberse introducido en judeoespañol como eternita, aunque la variante eternidad también se lee "judeoespañolamente". Su presencia en el poema tal vez busque conectar el saber de la kabalá a su contexto histórico peninsular de los siglos XII y XIII que estaba estrechamente relacionado con el diálogo entre las sabidurías monoteístas, en particular bajo el reinado de Alfonso x de Castilla. Dicho diálogo sucedió también a raíz de la vibrante escuela de Toledo dedicada a la traducción de textos teológicos, astronómicos y científicos del hebreo y el árabe al latín y al castellano, donde los sabios judíos tuvieron un rol significativo. ${ }^{35}$

Lo mismo sucede en el poema "Lo korolado", que igualmente se encuentra en la sección "De morideros". El poema intercala el español al djudezmo e introduce la presencia de Isaac Abravanel, pensador místico y estatista peninsular del siglo Xv — de las Coronas de Castilla y Portugal y las repúblicas de Nápoles y Venecia-, quien defendió la pertenencia de los judíos a la península, operando para detener el edicto de expulsión.

34 Además de ser el nombre de la letra, "beth", en hebreo, significa casa.

35 "Desafino en Toledo, transformo el latín en romance” (Gabbay, 2021, p. 10, v. 17).
E1 poema dice: "los eskritos/de abravanel/respiraderos son...//ojos de grandes biologias..." (pp. 37-38), y luego lo emparenta en código con el meshorer [poeta en hebreo] "LECNA LUAP", que reconocemos como Paul Celan.

Aquí Moscona juega con las posibilidades analógicas que otorga la gematria o numerología hebrea (Gabai, 2002, pp. 71-118), la cual adjudica un número místico a cada una de sus veintidós letras. Se considera que existe una relación cabalística entre nombres que comparten numerología.

El poema "Lo korolado" —que hace referencia al color rojo, pero también juega con la palabra korona que aparece en el primer poema "De efsuenyos" (p. 19) y lo relaciona con la dimensión Keter (corona), la dimensión existencial más alta estipulada por la ciencia de la kabalá- sugiere una identificación entre el sabio Abravanel y el poeta judío Paul Celan, pero por "cábala" — como es costumbre en gematria- ${ }^{36}$ encubre el nombre del poeta entremezclando sus letras "LECNA LUAP".

Para comprender los valores, debemos recobrar las palabras hebreas. Abravanel se escribe אברבנאל 286. Paul Celan se transcribe habitualmente פאול צלאן

36 La kabalá infiere que la verdad divina se manifiesta en una luminosidad a la que no debe ser expuesto el ser humano y, por lo tanto, el encubrimiento de la verdad es necesario como protección, de modo que los saberes de orden místico son codificados, siendo el valor 1 (de la alef $\mathrm{x}$ ) el supremo. A medida que el valor numerológico crece, se le considera más alejado de Keter. El trabajo del cabalista, que consiste en decodificar el lenguaje para indagar en la divinidad sin estar expuesto a la revelación directa, es una labor extremadamente cuidadosa y de santo valor. El poema de Moscona respeta entonces los mandatos cabalísticos, pero explica "porke el muncho decir / enflakeze los sekretos” (p. 38).

$37 I=\kappa ; 2=\beth ; 200=7 ; 2=\beth ; 50=\jmath ; l=\kappa ; 30=\zeta=286$. 
propuesta por Moscona, debemos transcribir

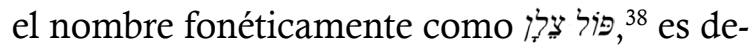
cir, retirando dos veces la letra alef $x$-que en ocasiones desempeña el rol de letra muda y en otras suena como la vocal [a]-. De este modo, el valor numérico de Paul [pol] Cel[a]n también es 286 . A través de esta equivalencia, Moscona establece la genialidad par del rabi [el sabio] y del meshorer [el poeta], y mediante esta operación también sugiere que poesía y mística se comunican ambas con lo divino.

El siguiente poema, "Otruna version", del poema "Lo korolado", habiéndose ya establecido la equivalencia entre ambas figuras, se permite trokar - concepto que aparece de modo insistente en el poemario y describe la labor gimétrica que troca letras por números y viceversa-, las historias de ambas, y así es que dice: "kuando raví abravanel se echo del puente" (p. 39), donde hace alusión al suicidio de Paul Celan en París a la edad de 49 años en 1970. El mismo poema explica, entonces, que este trueke entre figuras sea posible, ya que "lo savemos abravanel preziado: / la eternidad / de orejas esta enchida / i de ojos"; es decir, porque las dimensiones del tiempo y el espacio están conectadas y son permeables, Isaac Abravanel y Paul Celan pueden ser dos manifestaciones de la misma existencia en dimensiones temporales diferenciadas. Esta permeabilidad podría, ansina, darse también entre lenguas, dando pie a comprender el espacio intersticial al que se refería Juan Gelman en Dibaxu: un espacio místico donde las lenguas hermanas, el judeoespañol, el castellano, el aragonés, el catalán, el portugués, etc., pueden servir como mediaciones para viajar entre dimensiones temporales y, por qué no, desandar las acciones históricas hasta la retrotopía que nos llevaría a la Toledo humanista de Alfonso el Sabio.

$3880=פ ; 6=1 ; 30=7 ; 90=צ ; 30=\zeta ; 50=1 / 2=286$.
Para seguir el juego propuesto por la poeta, podemos argüir que 286 equivale también a la palabra 2 [pur], "lotería" y, por extensión, "suerte/destino". Esta idea aparece en el poema "La tripa", que menciona una tirada de cartas de tarot, donde la del colgado - número XII-, "el sakrifikado enkolgado del rovés / me mira la mirada miya", intercambia una mirada con la voz poética y dice: "malos signos ambezados [enseñados] / ande el ombre / da su no saver" (p. 42), y entonces, la mala suerte está racionalmente explicada por la falta de sabiduría. Esa lotería o destino a la que aduciría el número 286 aplicado a este poema se transluce en el verso "el mazal [la suerte] esta salado". ${ }^{39}$

Otro elemento recurrente en Ansina, que aporta a la cuestión cabalística, es el de la circularidad (que a veces es espiral), ya sea temáticamente hablando (poema "Un bomboniko", p. 22), por la relación entre comienzo y desenlace del poema ("Embrolyo en Fortaleza", pp. 24-25), o por un progresivo encabalgamiento entre versos ("De trokamientos", p. 20). El círculo se convierte incluso en "La kordela de Moebius". Esta posibilidad permite integrar la idea de que el saber procede del aspecto femenino de la divinidad, la Shejiná: "ainda diskuten / si el ojo del Dio / mos amasó con shejina / prinsipio de mujer tendra muestro saver?" (p. 51). ${ }^{40}$

La sección "De kreaziones i undimientos" insiste en el aspecto místico sefardí, mediante un epígrafe del Libro del esplendor, el Zohar -dado a conocer en Sefarad en el siglo xiII, pero atribuido a sabios del siglo II-, que hizo escuela

39 Sin embargo, el tarot no es un artefacto utilizado por los místicos judíos. Fue, al parecer, un cierto sincretismo pseudocabalista europeo el que, mediante la apropiación cultural de las veintidós letras del alefato, las adjudicó a cada una de las cartas del arcano menor.

40 La Shejiná es la presencia mística femenina de la cual se dice que acompañó a los y las exiliados/as sefardíes en los caminos a pie hacia la diáspora. 
en la ciudad de Safed (en la Tierra de Israel bajo el imperio otomano) entre los místicos sefaradíes expulsados y sus descendientes.

En dicha sección, la poeta presenta la ciencia del saber en el poema "La letra beth: el muro", pero también el secreto del no saber en el poema "Olvido", donde se aduce que, en el Jardín del Edén, hombre y mujer, habiendo accedido al árbol de la sabiduría, fueron aletargados tras la creación: "el dio barriyó su dedo // entre el labio de anriva / i la naris" (p. 46) y de este modo olvidaron todo lo que en un principio sabían. Esta escena corresponde a un intertexto de la Guemará, una de las dos partes que componen el Talmud de Babilonia. Dice en su traducción moderna al inglés:

And once the fetus emerges into the airspace of the world, an angel comes and slaps it on its mouth, causing it to forget the entire Torah, as it is stated: 'Sin crouches at the entrance' (Génesis 4:7) i.e., when a person enters the world he is immediately liable to sin due to his loss of Torah knowledge (Orden de la Pureza Ritual, Tratado de Nidá $30 \mathrm{~b}: 23){ }^{41}$

Con este trasfondo, el poema de Moscona concluye "rekodremos injuntos el olvido" (p. 47) yendo sólo en apariencia a contrapelo del mandamiento por la memoria $(Z j o r),{ }^{42}$ pero invitando a comprender precisamente el porqué del olvido. El poema emparenta la marca física del silencio impuesto por el ángel y la escritura, y a ambas las denomina "undimiento".

En Ansina se entremezclan la mística, la poesía y la ciencia, y esta combinación demuestra la

41 El Talmud (siglo v) está compuesto a grandes rasgos por la Misná y la Guemará, que es el comentario a la Torá oral, y alberga las discusiones rabínicas en torno a todos los aspectos de la vida judía (Sefariá, s. f.).

42 El mandamiento dice en Deuteronomio 25:19: "borrarás la memoria de Amalec de debajo del cielo; no lo olvidarás". riqueza del judeoespañol en boca de la autora mexicana, al mismo tiempo que establece una relación directa con la tradición hispano-judía medieval.

Antes de cerrar el volumen, la hablante se defiende metapoéticamente de la academia del judeoespañol:43 "profezores que pasan todo el diya eruktando danrivabasho, ke no konozen la lingua muestra...Meldan kuentos, sienten frazes ma estan al rovés... Dafuera adientro van a dar un veredikto?", y revaloriza su lengua más allá de la orfebrería de la nostalgia: "no se topa la lingua / solo para servir / kantikas o para enlazar / ermanos" (p. 54).

El poema se extiende en las posibilidades de la lengua, haciendo un recuento de lo que el mismo volumen hizo previamente y agregando astronomía, zoología y hasta anatomía (p. 65). Cierra: "el diavlo esta líbero / es linguista i entrenado" (p. 55).

Sin embargo, Ansina no carece de estrategias metalingüísticas que sustentan sus intereses, dejando de lado el método de la autotraducción.

\section{Dar o no dar: el artilugio metalingüístico entre autotraducción y glosario}

Si bien me he entrenado en el quehacer de la lengua y la autotraducción, no vengo a ejercer de diavlo. Los poemarios de Denise León y Myriam Moscona son fuente de sabiduría y, además, hacen mundo mediante la palabra djudezma, enriquecen la literatura sefardí, aportan poéticas donde la traducción y el multilingüismo ocupan un lugar preponderante, y como

43 La Akademia Nasionala del Ladino fue fundada en Israel en 2018. En un hecho, que no por ser histórico no deja de ser controvertido, la Academia Real Española la acogió entre la Asociación de Academias de la Lengua Española; sin embargo, la gran mayoría de hablantes e instituciones sefardíes se niega a adoptar las normativas hispanistas. 
resultado, extienden el horizonte hispano. E1 objetivo de este trabajo es comprender los mecanismos mediante los cuales esto se hace posible y analizar qué desencadena la chispa que estos encienden en el contexto macro de la literatura latinoamericana.

Dada la situación de precariedad geopolítica del djudezmo y el hecho de que las obras publicadas en las últimas décadas hayan sido producidas fuera de los marcos comunitarios o institucionales tradicionales, surgió la necesidad de publicar literatura en judeoespañol, acompañada por artilugios metalingüisticos, es decir, procedimientos por los cuales se mediatiza la lengua y se transmite a comunidades que leen otras lenguas, a través de plataformas editoriales de mediano alcance. Al mismo tiempo, el judeoespañol aprovecha su raíz y práctica románica, y destaca su potencial, al ser medianamente legible para lectores y lectoras de otras lenguas románicas, en particular el castellano y el portugués.

En el marco de estas prácticas metalingüísticas encontramos, sin embargo, una variedad de posturas que no son distantes unas de las otras. Estas consisten en acompañar los textos djudezmos de: 1) una traducción o autotraducción; 2) un glosario; 3) otras prácticas metalingüísticas que yuxtaponen el judeoespañol a otras lenguas, y 4) un pedido tácito de buena voluntad.

En tanto las obras judeoespañolas de Clarisse Nicoïdski, Juan Gelman, Denise León, Avner Pérez y, tardíamente, Marcel Cohen optaron por la traducción o autotraducción yuxtapuesta de sus textos para mediar con otras lenguas (castellano, francés, inglés, hebreo), Myriam Moscona opta, en la novela Tela de sevoya, por una estrategia múltiple: por un lado, naturaliza el judeoespañol dentro del texto castellano, de modo que las lectoras y los lectores se habitúan a su presencia; y, por otro lado, si considera que ciertas palabras o fragmentos necesitan explicación, yuxtapone a la palabra judeoespañola su equivalente en castellano, o bien produce una explicación metalingüística y metapoética que permiten el fluir de la lectura. ${ }^{44}$ En muchos sentidos, Moscona educa a sus lectores y lectoras hispanos/as en el judeoespañol y su cultura.

En Ansina, los fragmentos en castellano no juegan un rol metalingüístico, sino que representan una voz que se distingue del canon central. Sin embargo, Moscona sí introduce al final del volumen un glosario, que contiene la traducción al castellano de 125 palabras o expresiones - un pliego preciosamente diseñado, de color negro con letras plateadas-.

Además, la poeta introduce su poemario mediante un exordio, donde explicita por qué no adopta la estrategia architextual que impone la autotraducción.

Mientras diversos poetas y escritores dan testimonio de que se negaron a autotraducirse, ya sea por cuestiones relacionadas con el cansancio que conlleva la escritura prolongada, la situación de precariedad económica (Arrula-Ruiz y Manterola Agirrezabalaga, 2019) o la distancia que se crea con lo escrito una vez finalizada la labor (Whyte, 2002), Moscona relata que, tras la sacudida de Dibaxu, autotraducirse representó una "tentación" a la hora de publicar Ansina, ante todo porque su escritura también va en busca del intersticio "entre los dos sonidos" de los "dos castellanos" (2015, p. 11), sugerido por Gelman. Sin embargo, desiste:

[...] las cosas que sólo pueden ser dichas en una lengua y no en otra. [...] hay expresiones que solamente me brotan en ladino: el habla que me permite entrar en otra dimensión del tiempo, en una más íntima, familiar y primitiva (p. 11),

44 Por ejemplo: "Necesita comprar pasadores para aplacarse los rizos. [...] muy segura de lo que busca, aborda a una dependienta:

- Senyorita, kero merkar unas firketas para los kaveyos.

—¿Unas qué?

—Trokas, firketas" (Moscona, 2014, p. 7). 
y luego completa la idea que reconozco como intersticial en Gelman: "mi vida cotidiana me columpia en los siglos que se mecen entre el ladino y el español. El juego consiste en mezclar ambos tiempos sin atender la pureza" (Moscona, 2015, p. 11).

Abre así Moscona la opción —que hemos visto con claridad en la obra de Denise León-, del translingüismo de mestizaje; sin embargo, Moscona no mixtura las lenguas, sino que las yuxtapone. Esta apertura se suma a su voluntad de renovar el lenguaje, hablando en judeoespañol de ciencia, de amor, con humor, de mística y poesía. El resultado es un "despliegue musical" que, por un lado, restituye la vida plena y cotidiana al judeoespañol y, por otro, permite mostrar "las huellas que el español contemporáneo conserva de aquellas viejas pisadas" (p. 12). Con esto se reevalúa el parentesco especular entre ambas lenguas, al mismo tiempo que se da el debido espacio para reimpulsar al djudezmo en la literatura latinoamericana.

En el caso de los poemarios de Denise León, Poemas de Estambul y El saco de Douglas, la autotraducción cumple un rol estructural. Si bien sirve como herramienta metalingüística, el interés central va más allá de la mera "función fática" (Jakobson, 1963, cap. x) y los buenos modales editoriales; invita, de hecho, a instalarse en el intersticio y observar tanto las relaciones entre las lenguas - espacio desde el cual se podrá decolonizar la historia común-, como sus diferencias, y allí reintegrar la cultura sefardí, retirar el velo que la cubre, invitando a reconocer en ella la existencia de diversas otredades, que fueron borradas durante los últimos cinco siglos por el constante trabajo normalizador del Imperio español, sus vicerreynatos y las repúblicas poscoloniales que nos instruyen. Si entre "ambos castellanos" (según Gelman) reverberan significaciones y significancias, hay un mundo que se pierde cuando optamos por el monolingüismo.

Ni Moscona ni León, entonces, se muestran complacientes con el orden hispano impuesto desde la glotopolítica moderna. Sus trabajos se erigen en disidencia del canon latinoamericano hispanista. Hacen vanguardia, porque son pioneras en desarrollar la poesía djudezma en América Latina, pero no "modernizan" el judeoespañol, porque no se doblegan ante las normativas reales, sino que proponen no una versión de lo diverso, sino la diversidad en sí, permitiéndose variar incluso dentro de un mismo poemario ortografía y léxico, desafiando los consensos, haciendo honor al histórico polimorfismo de la palabra judeoespañola.

Si Moscona desecha el principio purista de la nación que se conformó a partir de la imposición monolingüista, porque habla desde una "lengua sin patria" (Ansina, 2015, p. 12), León se aplica plenamente al mestizaje que, en $E l$ saco de Douglas, se manifiesta como djudezmollano, por un lado, y en sordina, por el otro, como castellano intersticial. Fundamentalmente esto sucede en "Klara, 1939", donde el texto judeoespañol desapareció visualmente, pero su lirismo fue absorbido por el texto castellano, cuestión que se percibe en una cierta contaminación de su sintaxis. De este modo, el djudezmo permanece en el castellano y "brinca" - usando un vocablo de Moscona- a la lengua de las lectoras y los lectores, reverbera y pervive.

Finalmente, no es casual que esta propuesta disidente se produzca precisamente a través de la voz de poetas mujeres en un contexto histórico (Arnés et al., 2020) en el que ser mujer y ser poeta-mujer implican reinventar la voz y replantear preguntas acerca del género que habla en los poemas. En consonancia, hemos visto que también en el mundo sefardí la figura de la mujer-poeta resulta novedosa - sin embargo, las mujeres sefardíes traen el bagaje de siglos de romancero oral en sus voces-.

Los textos de León son especialmente convincentes en este sentido: dan voz a una diversidad de personas (madres, hijas, abuelas, 
niñas, críos) en distinguidos momentos de la historia; simbolizan los espacios intersticiales de la lengua y la identidad de género, a través del espacio sexual más recóndito de la anatomía femenina, "el saco de Douglas" — denominación del espacio vacio ubicado entre el útero y el recto. Estos espacios intersticiales se manifiestan, juegan en la palabra, tensan las posibilidades del lenguaje y la cultura, la suya, la compartida, las futuras.

Las obras analizadas muestran que la poesía en neodjudezmo es una "literatura menor", en el sentido en que conforma el corpus literario del continente, diferenciándose del castellano contemporáneo, resistiéndose a ser engullido por la "lengua mayor". Al mismo tiempo que propone una lengua desterritorializada, refuerza su cualidad transnacional intrínseca y supera las fronteras nacionales y continentales impuestas por las geopolíticas actuales.

Esa cualidad es la que le permite romper el cascarón de la pertenencia y ser más allá del espacio en el que nace, así como del cual proviene. En este sentido, es neo-djudezma, innova desde la intrínseca y múltiple judeolengua. En el juego y la tensión entre resefardización y rehispanización, el djudezmo abre un nuevo nido y crea aves de fuego para la poesía hispánica $y$ sefardí, valga bien la redundancia.

Sin embargo, el judeoespañol no es castellano, es una lengua otra con historia y características propias, que por ser, en efecto, otredad, puede convivir con el castellano en el marco de los registros romances. Difiero entonces de la definición de Gilles Deleuze y Félix Guattari (1975), quienes identificaron "la literatura menor" de Franz Kafka como manifestación de un registro judeo-alemán desterritorializado perteneciente a la minoría judía de Praga. Estos autores vieron, en el lenguaje de Kafka, una variante del alemán, en etéreo concierto con el ídish, triangulando una pertenencia germánica común. Su pensamiento revela una cierta jerarquía entre las lenguas, en cuanto comprenden el alemán como contenedora, a la vez que marginadora, del registro de Kafka. Por el contrario, no es mi objetivo establecer una jerarquía entre la poesía en neodjudezmo y la poesía latinoamericana en castellano, sino mostrar su convivencia, precisamente porque son dos identidades diferenciadas, y su posibilidad no expone el judeoespañol ni como "lengua de papel" ni como "artificio" (1975, pp. 29-30).

¿La autotraducción de la literatura judeoespañola y otros mecanismos metalingüísticos salvarán a la lengua de caer definitivamente en el vacío de la extinción? Si la poesía en neodjudezmo en América Latina logra plantar sus semillas, si la especie humana sale del antropoceno como portadora de lenguas, tal vez halle del otro lado, en aquella era que aún no podemos visualizar —el Chthuluceno, dirá Haraway (2019)—, una tierra fértil donde las voces, la transmisión y la vida se manifiesten en formas no violentas, sin olvido, colonización, ni devastación, donde trokemos distopías y retrotopías por culturas plurilingües simpoiéticas (Haraway, 2019, cap. 3, pp. 99-152) que generen parentescos solidarios y estén a salvo en su diversidad y sus diferencias. Después de todo, a la maldición / bendición de Babel... pertenecemos.

\section{Referencias}

Aizenberg, E. (2003). Sefardíes y neosefardíes en la literatura latinoamericana. En N. Rehrmann (Ed.), El legado de Sefarad en la historia de la literatura de América Latina, España, Portugal y Alemania (pp. 49-58). Amarú.

Aki Yerushalayim. (2021, marzo) (104). https://esefarad.com/?p=103237 23.06.2021

Alvar, M. (2000). Acepciones. En El ladino, judeo-español calco (pp. 19-35). Real Academia de la Historia.

Armistead, S. G. y J. H. Silverman (1982). En torno al romancero sefardí (hispanismo y balcanismo de la tradición judeo-española). Seminario Mendéndez Pidal. 
Arnés, L. A., Domínguez, N. y Punte, M. J. (2020). Historia feminista de la literatura argentina, un proyecto. En L. A. Arnés, N. Domínguez y M. J. Punte (Coords.), En la intemperie. Poéticas de la fragilidad y la revuelta (vol. 5, pp. 11-14) de L. Arnés, N. Domínguez y M. J. Punte (Dir.), Historia feminista de la literatura argentina. Eduvim.

Arrula-Ruiz, G. y Manterola Agirrezabalaga, E. (2019). No a la autotraducción. Razones para renunciar a la traducción de obra propia en el contexto de las relaciones asimétricas entre el castellano y el euskera. En L. Bujaldón de Esteves et al. (Eds.), La autotraducción literaria en contextos de habla hispana. Europa y América (pp. 241-260). Palgrave Macmillan.

Asuero, P. M. y Gerson Sarhon, K. (Eds.) (2007). Ayer y hoy de la prensa en judeoespañol. Isis.

Attig, R. (2012). Did the Sephardic Jews speak ladino? Bulletin of Spanish Studies, 89(6), 831838. https://doi.org/10.1080/14753820.201 2.712320

Avni, H. (2003). Sefardíes occidentales y orientales en América Latina: realidad histórica y actual. En N. Rehrmann (Ed.), El legado de Sefarad en la historia de la literatura de América Latina, España, Portugal y Alemania (pp. 17-33). Amarú.

Balbuena, M. R. (2016). Homeless tongues. Stanford University Press.

Balbuena, M. R. (2012). Judeo-Spanish texts in Latin American genres: Language revival and national identity in contemporary Argentina. En H. Pomeroy, Ch. J. Pountain y E. Romero (Eds.), Selected papers from the Fifteenth British Conference on Judeo-Spanish Studies (pp. 3749). Queen Mary University of London. https://www.yumpu.com/en/document/ view/30124004/judeo-spanish-texts-in-latin-american-genres-language-revival-

Balbuena, M. R. (2009). Dibaxu. A comparative analysis of Clarisse Nicoïdski's and Juan Gelman's Bilingual Poetry. Romance Studies, 27 (4), 283-297. https://doi.org/10.1179/02639 9009X12523296128876

Bernardini, P. y Fiering, N. (Eds.). (2001). The Jews and the expansion of Europe to the West 14501800. Berghan Books.
Bonneuil, C. y Fressoz, J.-B. (2013). L'événement Anthropocène. La Terre, l'histoire et nous. Le Seuil.

Borovaya, O. (2017). How old is ladino literature? En M. Şaul y J. I. Hualde (Eds.), Sepharad as imagined community. Language, history and religion from the Early Modern Period to the 21 $1^{\text {st }}$ Century (capítulo 3, pp. 43-52). Peter Lang.

Bunis, D. M. (2011). Judezmo glossaries and dictionaries by native speakers and the language ideologies behind them. En W. Busse y M. Studemund-Halévy (Eds.), Lexicología y lexicografia judeoespañolas (pp. 339-431). Peter Lang.

Bunis, D. M. (2017). Judezmo (Ladino). En L. Kahn y A. D. Rubin (Eds.), Handbook of Jewish languages (pp. 366-451). Brill.

Casanova, P. (2008 [1999]). La République mondiale des Lettres. Editions du Seuil.

Cassani, A. (2019a). "Curilada oscuridá". Los versos judeoespañoles de Clarisse Nicoïdski. En Una lengua llamada patria. El judeoespañol en la literatura sefardi contemporánea (pp. 5-22). Anthropos.

Cassani, A. (2019b). "No ay realitad sino en las palabras". La Carta a Antonio Saura de Marcel Cohen y su autotraducción. En A. Cassani, Una lengua llamada patria. El judeoespañol en la literatura sefardí contemporánea (pp. 23-40). Anthropos.

Cassani, A. (2019c). Latinoamérica sefardí. En A. Cassani, Una lengua llamada patria. El judeoespañol en la literatura sefardí contemporánea (pp. 55-80). Anthropos.

Cohen, M. (1985). Letras a un pintor ke kreya azer retratos imaginarios: por un Sefardi de Turkia ke se akodra perfektamente de kada uno de sus modeles. Almarabu.

Deleuze, G. y Guattari, F. (1975). Kafka. Pour une littérature mineure. Éditions de Minuit.

Della Pergola, S. y Schmelz, U. O. (2006). Demography. En F. Skolnik (Ed.), Encyclopedia judaica (vol. 5, pp. 553-557). Thomson Gale.

Díaz-Mas, P. (1986). Los sefardíes. Historia, lengua y cultura. Riopiedras. 
Díaz-Mas, P. (1994). Poesía oral sefardí. Esquío.

Díaz-Mas, P. y Martín Ortega, E. (Eds.). (2016). Mujeres sefardies lectoras y escritoras, siglos XIX$X X I$. Iberoamericana-Vervuert.

El Amaneser (2005-2021). https://sephardiccenter. wordpress.com/el-ameneser/

Elkin, J. L. (1995). Centaur on the roof: Can a Neo-Sephardic culture emerge in Latin America? Shofar, 13(2), 1-15. https://doi.org/10.1353/ sho. 1995.0032

eSefarad (2008-2021). https://esefarad.com/

Fabry, G. (2001). El diálogo interlingüístico en Dibaxu (1994) de Juan Gelman. En R. de Maesener, M. E. Ocampo y Vilas y A. Van Hecke (Eds.), Convergencias e interferencias: escribir desde los borde(r)s (pp. 93-102). Universidad Complutense.

Feierstein, R. (2021). Memoria e identidad. Las avenidas del barrio judio en la ciudad literaria. Acervo Cultural, Hispamérica.

Foffani, E. A. (1995). La lengua salvada. Acerca de dibaxu de Juan Gelman. En R. Spiller (Ed.), Culturas del Río de la Plata (1973-1995). Transgresión e intercambio (pp. 183-202). Vervuert Verlag.

Gabai, H. (2002). Judaism, mathematics, and the Hebrew calendar. Jason Aronson.

Gabbay, C. (2006). Com/posiciones: los poemas de Eliezer Ben Jonon: heteronimia, simbolismo y exilio. En F. Moreno (Ed.), La memoria de la dictadura (pp. 337-345). Ellipses.

Gabbay, C. (2020a). Babilonia y revolución en España: prácticas de escritura cosmopolita de una miliciana / Mika Feldman Etchebehere. En J. Kölbl, I. Orlova y M. Wolf (Eds.), ¿Pasarán? Kommunikation im Spanischen Bürgerkrieg. Interacting in the Spanish Civil War (pp. 82-99). New Academic Press.

Gabbay, C. (2020b). El onceavo mandamiento: memoria del fuego en la literatura judía y feminista de la guerra civil española. En E. Kahan, A. Raber y W. Wechsler (Eds.), Hacer patria. Estudios sobre la vida judia en Argentina (pp. 31-67). Teseo.

Gabbay, C. (2021). ¡Genealogías, habibti! Mozaika Magazine, 8, 10-11.

Gabbay, C. (en prensa). L'autotraduction de Mika Feldman Etchebehere ou écriture à deux plumes pour un pacte cosmopolite. En C. Lavail y A. Taillot (Eds.), Crisol, Université Paris-Nanterre.

García Moreno, A. (2006). Innovación y arcaísmo en la morfosintaxis del judeoespañol clásico. Revista Internacional de Lingüistica Iberoamericana, 4(2-8), 35-51. https://www.jstor.org/ stable/41678239

García Moreno, A. (Dir.) (2013- ). DHJE, Diccionario histórico del judeoespañol. Consejo Superior de Investigaciones Científicas. http://esefardic. es/dhje

Gasquet, A. (2007). Avant-propos. L'hospitalité des langues ou une invitation à la xénoglossie. En A. Gasquet y M. Suárez (Eds.), Ecrivains multilingues et écritures métisses: L'hospitalité des langues (pp. 7-16). Presses Universitaires Clermont.

Gelman, J. (1982). Citas y comentarios. Visor.

Gelman, J. (1992). Lo judío y la literatura en castellano. Hispamérica, 62, 83-90. https:// ur.booksc.eu/book/46385213/ac91cf

Gelman, J. (1994). Dibaxu. Seix Barral.

Goldberg, F. F. (2013). "Carta de naturalización": femineidad, judaísmo y universalidad en la poesía de Myriam Moscona. Chasqui: Revista de Literatura Latinoamericana, (4), 192-202.

Haraway, D. J. (2019). Seguir con el problema. Generar parentesco en el Chthuluceno. Consonni.

Harris, T. K. (2011). The state of ladino today. European Judaism: A Journal for the New Europe, 44(1), 51-61.

Hassán, I. M. (2004). ¿Es el ladino judeoespañol calco? Quaderns de Filologia. Estudis Lingüistics, 9, 87-99. https://ojs.uv.es/index.php/qfilologia/article/view/5119

Hokenson, J. W. y Munson, M. (2007). The bilingual text. History and theory of literary self-translation. St. Jerome Publishing.

Jakobson, R. (1963). Essais de linguistique générale. Minuit.

Koén Sarano, M. (2009). Dicsionario ladino-ebreo, ebreo-ladino. Kaza Editora S. Zack.

Ladinokomunita (s. f.). http://www.sephardicstudies.org/komunita.html 
Laplantine, F. y A. Nouss (2001). Métissages, de Arcimboldo à Zombi. Pauvert.

León, D. (2008). Poemas de Estambul. Alción.

León, D. (2009). La historia de Bruria. Simurg.

León, D. (2011). El saco de Douglas. Paradiso.

León, D. (2013a). El mundo es un hilo de nombres. Sobre la poesía de José Kozer. Ed. Unión.

León, D. (2013b). Templo de pescadores. Alción.

León, D. (2014). Poemas de Middlebury. Huesos de Jibia.

León, D. (2019). Mesa de pájaros. Bajo la Luna.

Lévy, I. J. (1989). And the world stood silent. Sephardic poetry of the Holocaust. University of Illinois Press.

Lindstrom, N. (2017). La pérdida y la destrucción en la poesía visionaria de Myriam Moscona. Tintas, (7), 33-44. https://riviste.unimi.it/index.php/tintas/article/view/9371

Lockhart, D. B (2018). The semiotics of Djudeo-Espanyol in recent works by Myriam Moscona. iMex Revista, 7(14), 110-121. https://doi.org/10.23692/iMex.14.9

Mancheva, D. (2014). Diccionarios por y para sefardíes. Sinopsis de la lexicografía del judeoespañol oriental. Maestros de la Filología, 14, s. p. https://www.researchgate.net/publication/314396652_Diccionarios_por_y_para_ sefardies_Sinopsis_de_la_lexicografia_del_judeoespanol_oriental

Martín Ortega, E. (2011). I una boz ke es la manyana: El judespañol como lengua del rescate en la obra poética de Denise León. En O. Caballero Arias, E. F. Chávez y B. Ripoll Sintes (Eds.), Del verbo al espejo. Reflejos y miradas de la literatura hispánica (pp. 353-361). PPU.

Minervini, L. (2002). La formación de la koiné judeoespañola en el siglo xvi. Revue de Linquistique Romance, 66, 497-512. https://www.e-periodica.ch/cntmng?pid=rlr-001:2002:66::673

Moscona, M. (1983). Último jardín. El Tucán de Virginia.

Moscona, M. (1992). El árbol de los nombres. Cuarto Menguante.
Moscona, M. (2006). Negro marfil. Universidad del Claustro de Sor Juana.

Moscona, M. (2015). Ansina. Ediciones Vaso Roto.

Moscona, M. (2014 [2012]). Tela de sevoya. Acantilado.

Moscona, M. (2020). La muerte de la lengua inglesa. Almadía.

Moscona, M. y J. Sefamí (Eds.) (2013). Por mi boka. Textos de la diáspora sefardí en ladino. Lumen.

Muñiz-Huberman, A. (1989). La lengua florida. Antología sefardi. Universidad Nacional Autónoma de México, Fondo de Cultura Económica.

Nehama, J. (2003 [1977]). Dictionnaire du judéo-espagnol. Consejo Superior de Investigaciones Científicas, Reedición de Les Editions de la Lettre Sépharade.

Nicoïdski, C. (1978). Lus ujus, las manos, la boca. Baard Editions.

Nissán, R. (1992). Novia que te vea. Penguin Random House México.

Nissán, R. (1996). Hisho que te nazca. Plaza \& Janés.

Pascual, J.A. (2008). La lengua sefardí hoy y mañana (Mesa redonda). En I. M. Hassan, R. Izquierdo Benito y E. Romero (Eds.), Sefardies: Literatura y lengua de una nación dispersa (pp. 145154). Universidad Castilla-La Mancha.

Pérez, A. (1986). Siniza y fumo. Hebreo y ladino. Sefarad (Caspit).

Pérez, A. (1996). Ashan va-efer. Inglés y ladino. Maale Adumim.

Quintana Rodríguez, A. (2011). Geografia lingüistica del judeoespañol. Peter Lang.

Refael Vivante, S. (2008). Un grito en el silencio. La poesía sobre el Holocausto en lengua sefardí: estudio $y$ antología. Tirocinio.

Refael Vivante, S. (2010). "Regaladas de sus madres": Judeo-Spanish women's poetry on the Holocaust. European Judaism: A Journal for the New Europe, 43(2), 76-90. https://doi. org/10.3167/ej.2010.430208

Refael, S. (2020a). The words that replace the elusive past: Some recent ladino poetic responses. 
En S. J. Brenneis y G. Herrmann (Eds.), Spain, the Second World War and the Holocaust. History and representation (pp. 567-585). University of Toronto Press. https://doi. org/10.3138/9781487532505-035

Refael, S. (2020b). Ladino kan veajshav (hebreo). Universidad de Tel Aviv.

Robert-Nicoud, É. (2019). Irremplaçables. Stock.

Romero Sued, S. (2014). Dibaxu, de Juan Gelman: diáspora de la poesía en las galaxias de la transcreación. Aisthesis, (55), 85-95. https:// doi.org/10.4067/S0718-71812014000100006

Romero, E. (1992). Los sefardíes. Revista de la Asociación Europea de Profesores de Español, (40-41), 3751. https://cvc.cervantes.es/ensenanza/biblioteca_ele/aepe/pdf/revista_40-41_23-24_92/ revista_40-41_23-24_92_05.pdf

Rulfo, J. (1997). Pedro Páramo y El llano en llamas. Planeta.

Sánchez-Pérez, M. (2019). El Quijote en judeoespañol. Estudio y edición de los fragmentos publicados en los periódicos sefardies El Amigo de la Famiya (Constantinopla, 1881) y La Boz de Oriente (Estambul, 1931). Tirocinio.

Sefariá (s. f.). https://www.sefaria.org/Niddah.30b.23?lang=bi

Steffen, W., Broadgate, W., Deutsh, L., Gaffney, O. y Ludwig, C. (2015). The trajectory of the anthropocene: The great acceleration. The Anthropocene Review, 2(1), 81-98. https://doi. org/10.1177/2053019614564785

Szurmuk, M. (2019). Introducción. En M. Szurmuk (Ed.), Josep Sabah. Entre lenguas y mundos: las cartas de un maestro de la Alliance Israélite Universelle desde el Litoral (pp. IX-XXVIII). Eduner.

Vidal Sephiha, H. (1994). Caracterización de la Biblia de Ferrara. En I. M. Hassán y Á. Berenguer Amador (Eds.), Introducción a la Biblia de Ferrara (pp. 299-314). Universidad de Sevilla, Consejo Superior de Investigaciones Científicas.

Whyte, C. (2002). Against self-translation. Translation and Literature, 11(1), 64-71.

Cómo citar este artículo: Gabbay, C. (2022). Neodjudezmo en la lírica latinoamericana disidente: la construcción de registros intersticiales entre la autotraducción y el glosario. Mutatis Mutandis, Revista Latinoamericana de Traducción, 15(1), 65-94. https://doi.org/10.17533/udea.mut. v15n1a05 